\title{
A Seventeen Multilevel High-Power Application Inverter with Low Total Harmonic Distortion
}

\author{
Ajmal Farooq, ${ }^{1}$ Shanshan Tu $\left(\mathbb{D}^{2},{ }^{2}\right.$ Fiaz Ahmad, ${ }^{3}$ Muhammad Zeeshan Malik $\left(\mathbb{D},{ }^{4}\right.$ \\ Obaid U. Rehman, ${ }^{5}$ Ghulam Hafeez, ${ }^{1}$ and Sadaqat ur Rehman ${ }^{6}$ \\ ${ }^{1}$ Department of Electrical Engineering, University of Engineering \& Technology, Mardan, Pakistan \\ ${ }^{2}$ Engineering Research Center of Intelligent Perception and Autonomous Control, Faculty of Information Technology, \\ Beijing University of Technology, Beijing 100124, China \\ ${ }^{3}$ Department of Electrical \& Computer Engineering, Air University, Islamabad, Pakistan \\ ${ }^{4}$ School of Electronics and Information Engineering, Taizhou University, Taizhou, 318000, Zhejiang, China \\ ${ }^{5}$ Department of Electrical Engineering, Sarhad University of Science \& IT, Peshawar, Pakistan \\ ${ }^{6}$ Department of Computer Science, National Institute, Mian Wali, Pakistan \\ Correspondence should be addressed to Shanshan Tu; sstu@bjut.edu.cn
}

Received 21 March 2021; Revised 23 July 2021; Accepted 12 August 2021; Published 3 September 2021

Academic Editor: Laurentiu Fara

Copyright (C) 2021 Ajmal Farooq et al. This is an open access article distributed under the Creative Commons Attribution License, which permits unrestricted use, distribution, and reproduction in any medium, provided the original work is properly cited.

\begin{abstract}
In this paper, a new topology of multilevel inverter (MLI) is designed with a fewer number of components and low total harmonic distortion (THD) for high-power photovoltaic (PV) systems. The key limitations of conventional MLI topologies are high total harmonic distortion (THD) and the use of a large number of switching components due to which the cost of the overall inverter is high. In conventional MLI, THD can be significantly reduced by the addition of a large value filter element at the input side; however, it will result in increased size and cost. Thus, achieving a pure sinusoidal AC at the output and to maintain a low THD level is a major issue in conventional MLIs. The proposed MLI has the advantage of decreasing the output THD by using a modified form of the cascaded H-Bridge structure and sine pulse width modulation technique. The proposed inverter consists of 6 unidirectional switches and 2 bidirectional switches, and there is no extra requirement for additional voltage balancing capacitors or clinching diodes. The individual switching states and SPWM operation for generating the gate pulses of the proposed MLI are discussed in detail. Relevant waveforms are plotted, equations are derived, and mathematical analysis is carried out. A steady-state analysis of the proposed MLI demonstrates an output voltage with 17 levels while using only four DC sources. Simulation results of the proposed MLI for single-phase and three-phase structures are obtained, and comparison is carried out with existing MLI topologies which shows that the proposed MLI has significantly low THD and better performance. From the results, it is clear that the proposed MLI has a THD of $3.52 \%$ in comparison with four conventional MLIs whose THDs are 6.1\%, 6.63\%, 7.3\%, and 9.93\%. Moreover, the proposed MLI generates 17 voltage levels by using only 08 switching devices, whereas the conventional MLIs use more than 10 switching devices for the generation of 15 voltage levels.
\end{abstract}

\section{Introduction}

Multilevel inverters are a candidate topology for highvoltage and high-power applications in industries nowadays. Multilevel inverters offer various advantages including low THD, simple to deal with, and compact size as compared to conventional inverters [1-4]. Research is ongoing on
MLIs, and there are various topologies available in the literature. The selection of MLI for an application is based upon cost, complexity, losses, and THD. Figure 1 shows the shape of the output voltage of a 7-level MLI [5-9].

A diode-clamped MLI is presented in $[10,11]$. As clear by its name, diode-clamped MLI requires a propping device. Capacitors are used for the division of DC voltage into 


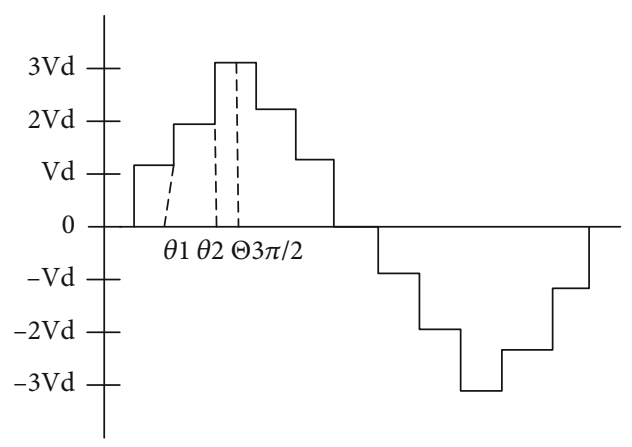

Figure 1: 7-level MLI.

switches. $N-1$ switch sets are necessary for the $N$ number of required levels. The drawbacks of this topology are that in between number of diodes and the count of levels, the quadratic association is very difficult to compute, especially when it ends up upsetting when the count of levels gets higher $[12,13]$.

A flying capacitor MLI is very much similar to the diodeclamped MLI. The flying capacitor MLI requires that the capacitor must be previously charged for its operation. Besides the benefits of low THD, precharging of capacitors is troublesome [14].

The fundamental and well-understood topology is cascaded H-Bridge MLI. This type of MLI has been utilized for single as well as three-phase transformations. This type of MLI utilizes a certain type of $\mathrm{H}$-Bridge that comprises a diode as well as switches. During an instance, 3 levels of voltage are necessary for MLI. It can be achieved by a solitary or single $\mathrm{H}$-Bridge in cascaded $\mathrm{H}$-Bridge MLI. In cascaded $\mathrm{H}$ Bridge MLI, fewer components like capacitors and switches are required. It requires fewer segments when contrasted with different procedures. But every H-bridge MLI requires an independent DC source [5].

A switch ladder MLI is presented in [6] which is a modified form of cascaded H-Bridge MLI. This MLI utilizes few components and provides an output waveform that is almost sine waveform, which has low THD. This topology also uses more components [15].

A simple circuit (Op-Amp) controlled voltage source MLI is presented that utilized PWM strategy for harmonics decrease and demonstrates the best way to produce SPWM distinctive Op-Amp circuits where the passive type of filters is utilized toward the output for the reduction of harmonics; in this way, the components of the inverter are increased [16].

Another inverter named cascaded H-Bridge MLI with a phase disposition technique is presented in [17]. This work introduced a single phase of cascaded H-bridge MLI, and more elevated levels of voltages were attained with less number of parts utilizing the phase disposition system. The number of voltage levels was enlarged; however, this circuit incited high THD [17].

Reduced switch count multilevel inverter topologies using the cascaded structure and switched capacitor techniques have been presented to lower the THD level and reduce the number of switching devices [18-20].

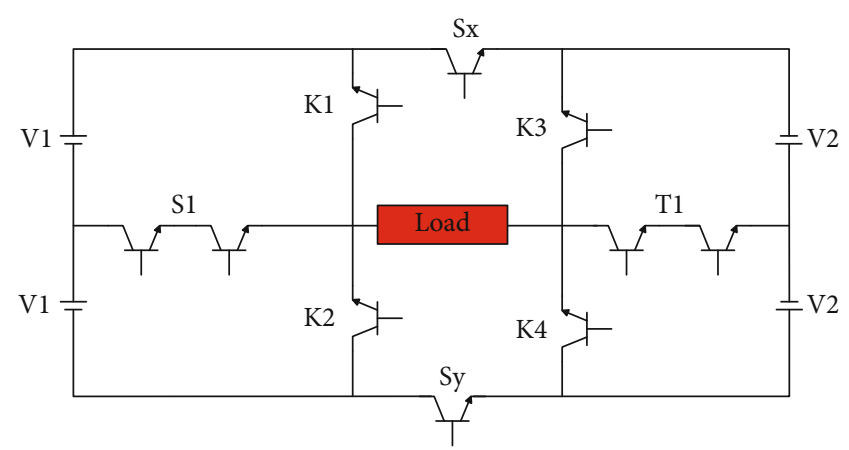

Figure 2: Proposed MLI.

\section{Proposed MLI}

There are numerous kinds of MLI available in the market. A lot of research is going upon MLI. The layout circuit of the proposed work is displayed in Figure 2. It is an altered elucidation of the H-bridge type of MLI topology. The fundamental bit of leeway of the presented work as compared to the previously discussed work is that we can achieve more output levels by utilizing a minimum number of components. The proposed MLI has fewer switches and offers low total harmonic distortion.

The proposed MLI uses two bidirectional switches and six unidirectional switches. Each bidirectional switch is comprised of two IGBTS; hence, there are ten IGBTs and the number of independent power supplies is four. So the number of circuit elements is not much more. The more noteworthy thing in the proposed topology is that it can generate 17 levels with only eight switches. The number of levels and fewer switches assumes a significant job in the efficiency of the inverter. The increased level in output voltage demonstrates that this inverter has a low THD.

\section{Steady-State Analysis of Proposed MLI}

The operation of the proposed MLI is such that these ten switches are turned "on" and "off" at regular intervals by using sinusoidal pulse width modulation (SPWM). This is achieved by turning the different switches "on" assigning them 1 in binary form. The other switches are considered "off," assigning them 0 in binary form. In this way, the switching pattern of all the switches can be determined.

3.1. The $1^{\text {st }}$ Switching Pattern. In the first switching state pattern, the switches $K_{1}, K_{3}$, and $S_{x}$ are turned "on" and the switches $K_{2}, K_{4}, S_{1}, T_{1}$, and $S_{y}$ are turned "off," and the closed-loop path can be seen as shown in Figure 3. The output voltage is equal to zero as there is no available path for the input voltage to finish the loop.

So $V_{\text {out }}$ is

$$
V_{\text {out }}=0 \text {. }
$$

3.2. The $2^{\text {nd }}$ Switching Pattern. In the second switching state pattern, the switches $S_{1}, K_{4}$, and $S_{y}$ are turned "on" and the 


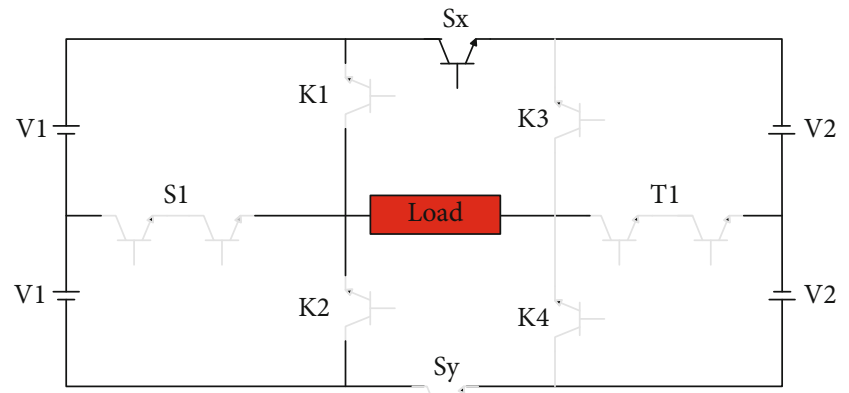

Figure 3: Current flow for the $1^{\text {st }}$ switching pattern.

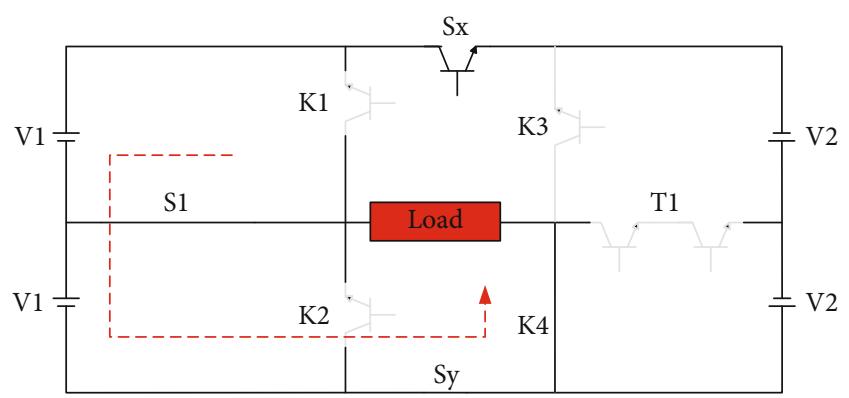

Figure 4: Current flow for the $2^{\text {nd }}$ switching pattern.

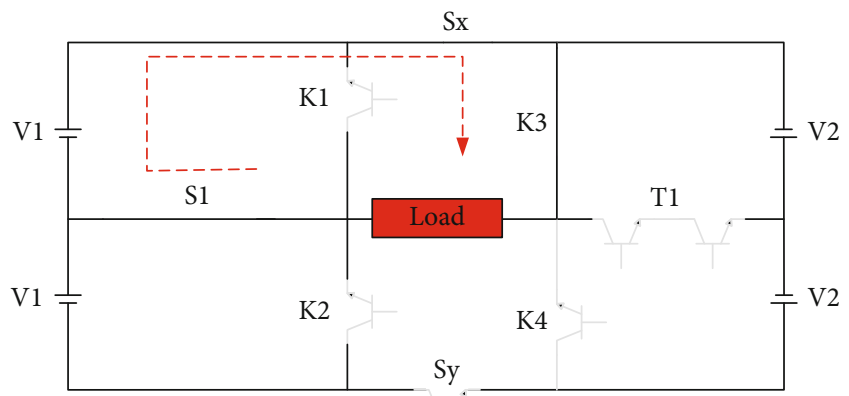

Figure 5: Current flow for the $3^{\text {rd }}$ switching pattern.

switches $K_{1}, K_{2}, K_{3}, T_{1}$, and $S_{x}$ are kept "off," so the circuit diagram can be visualized as in Figure 4.

So $V_{\text {out }}$ is

$$
V_{\text {out }}=\mathrm{V}_{1} \text {. }
$$

3.3. The $3^{\text {rd }}$ Switching Pattern. In the third switching state pattern, the switches $S_{1}, K_{3}$, and $S_{x}$ are turned "on" and the switches $K 1, K_{2}, K_{4}, T_{1}$, and $S_{y}$ are kept "off," so the circuit diagram can be visualized as in Figure 5.

So $V_{\text {out }}$ is

$$
V_{\text {out }}=-V_{1} \text {. }
$$

3.4. The $4^{\text {th }}$ Switching Pattern. In the fourth switching state pattern, the switches $T_{1}, K_{2}$, and $S_{y}$ are turned "on" and

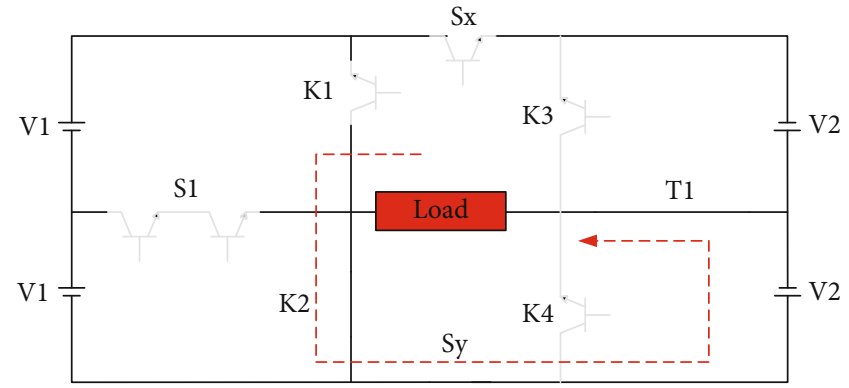

FIgure 6: Current flow for the $4^{\text {th }}$ switching pattern.

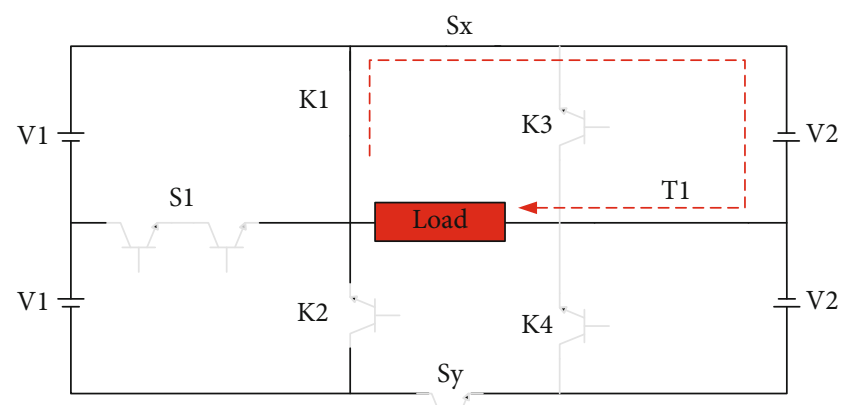

FIgUre 7: Current flow for the $5^{\text {th }}$ switching pattern.

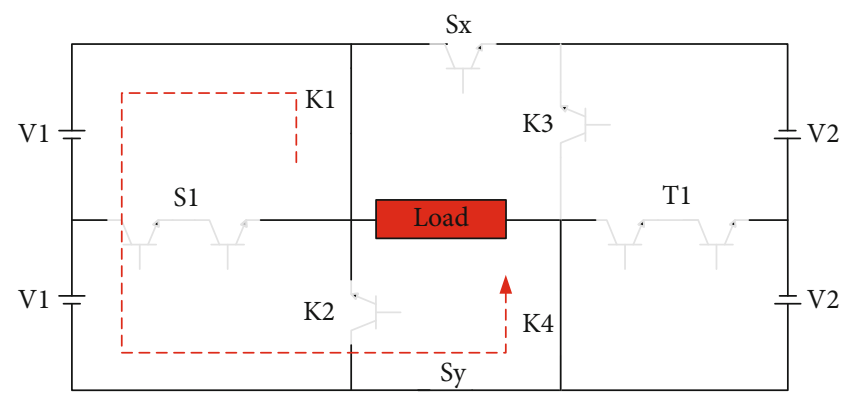

Figure 8: Current flow for the $6^{\text {th }}$ switching pattern.

the switches $K_{1}, K_{3}, K_{4}, S_{1}$, and $S_{x}$ are kept "off," so the circuit path is visualized as in Figure 6.

So $V_{\text {out }}$ is

$$
V_{\text {out }}=V_{2} \text {. }
$$

3.5. The $5^{\text {th }}$ Switching Pattern. In the fifth switching state pattern, the switches $T_{1}, K_{1}$, and $S_{x}$ are turned "on" and the switches $K_{2}, K_{3}, K_{4}, S_{1}$, and $S_{y}$ are kept "off," so the circuit diagram can be visualized as shown in Figure 7 .

So $V_{\text {out }}$ is

$$
V_{\text {out }}=-V_{2}
$$

3.6. The $6^{\text {th }}$ Switching Pattern. In the sixth switching state pattern, the switches $K_{1}, K_{4}$, and $S_{y}$ are turned "on" and the switches $K_{2}, K_{3}, S_{1}, T_{1}$, and $S_{x}$ are kept "off," so the circuit diagram can be visualized as depicted in Figure 8. 


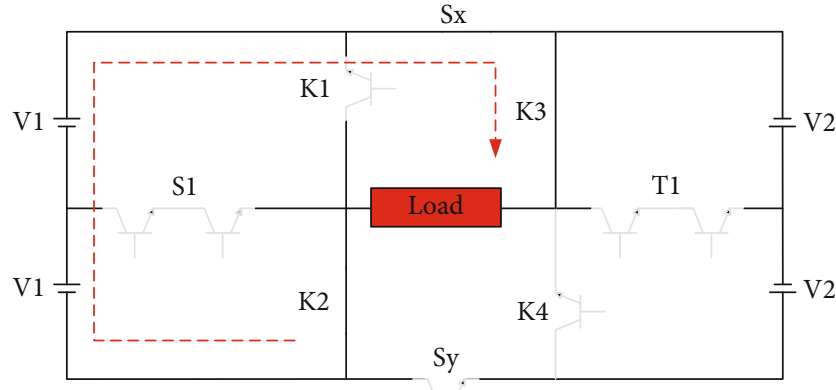

Figure 9: Current flow for the $7^{\text {th }}$ switching pattern.

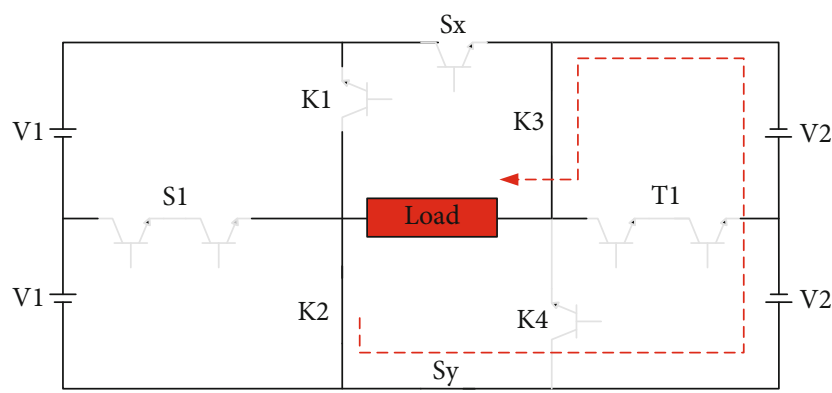

FIgure 10: Current flow for the $8^{\text {th }}$ switching pattern.

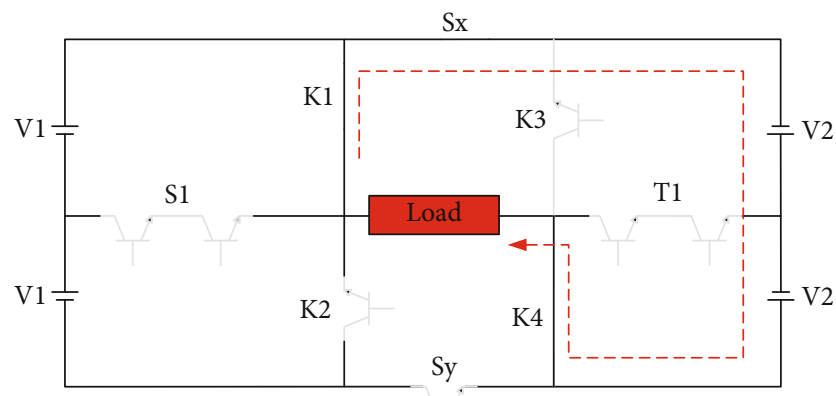

FIGURE 11: Current flow for the $9^{\text {th }}$ switching pattern.

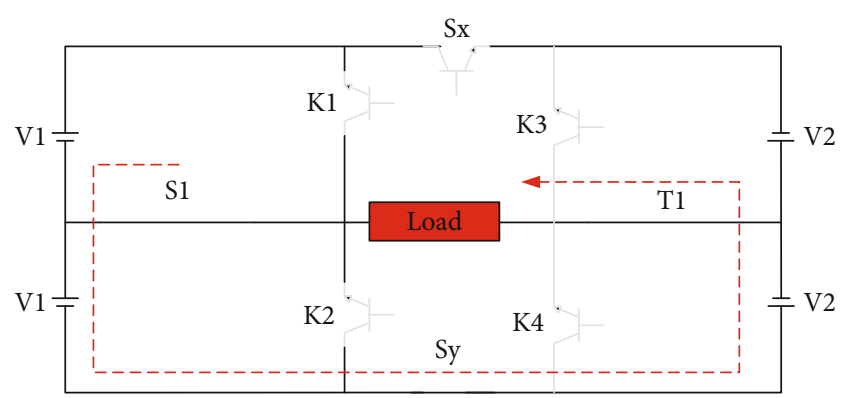

FIGURE 12: Current flow for the $10^{\text {th }}$ switching pattern.

So $V_{\text {out }}$ is

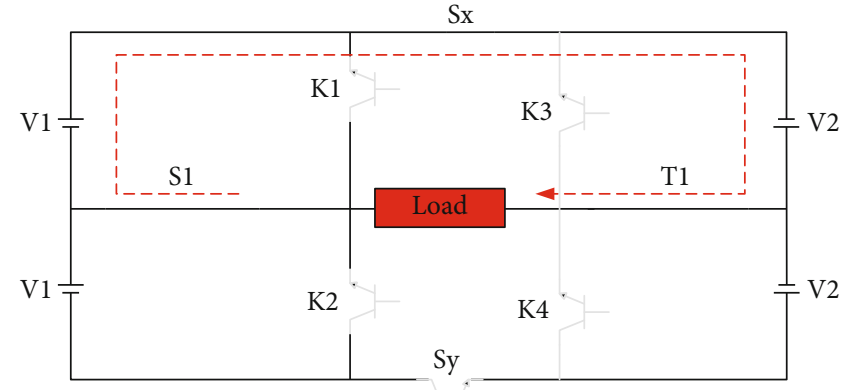

FIgURE 13: Current flow for the $11^{\text {th }}$ switching pattern.

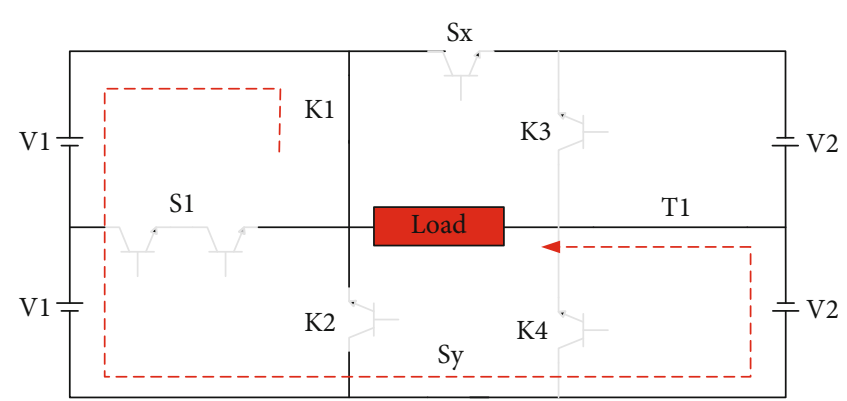

FIgURE 14: Current flow for the $12^{\text {th }}$ switching pattern.

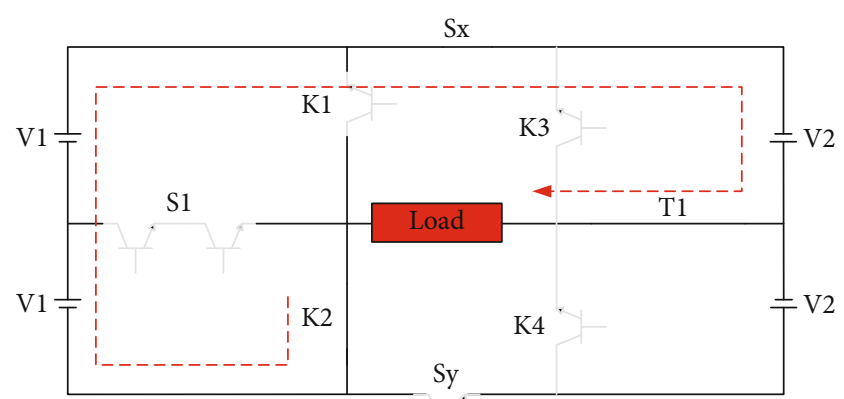

FIGURE 15: Current flow for the $13^{\text {th }}$ switching pattern.

3.7. The $7^{\text {th }}$ Switching Pattern. In the second switching state pattern, the switches $S_{x}, K_{2}$, and $K_{3}$ are turned "on" and the switches $K_{1}, K_{4}, T_{1}, S_{1}$, and $S_{y}$ are kept "off," so the circuit diagram can be visualized as depicted in Figure 9.

So $V_{\text {out }}$ is

$$
V_{\text {out }}=-2 V_{1}
$$

3.8. The $8^{\text {th }}$ Switching Pattern. In the eighth switching state pattern, the switches $K_{2}, K_{3}$, and $S_{y}$ are turned "on" and the switches $K_{1}, K_{4}, S_{1}, T_{1}$, and $S_{x}$ are turned "off," so the circuit diagram can be visualized as shown in Figure 10.

So $V_{\text {out }}$ is

$$
V_{\text {out }}=2 V_{1} \text {. }
$$

$$
V_{\text {out }}=2 V_{2} \text {. }
$$




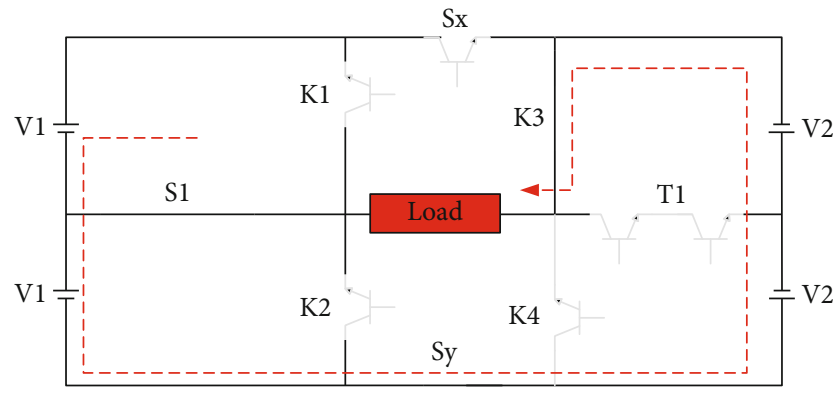

FIGURE 16: Current flow for the $14^{\text {th }}$ switching pattern.

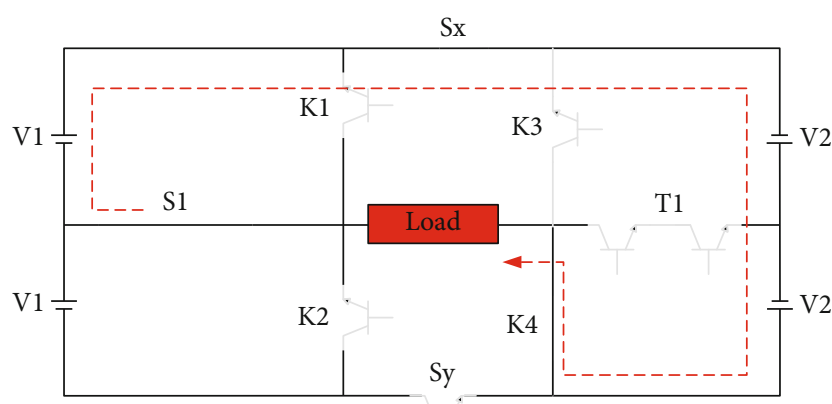

FIGURE 17: Current flow for the $15^{\text {th }}$ switching pattern.

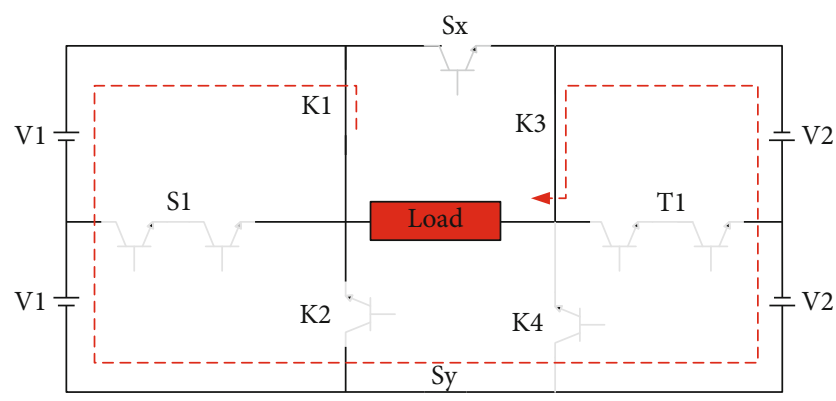

FIGURE 18: Current flow for the $16^{\text {th }}$ switching pattern.

3.9. The $9^{\text {th }}$ Switching Pattern. In the ninth switching state pattern, the switches $K_{1}, K_{4}$, and $S_{x}$ are turned "on" and the switches $K_{2}, K_{3}, S_{1}, T_{1}$, and $S_{y}$ are turned "off," so the circuit diagram can be visualized as depicted in Figure 11.

So $V_{\text {out }}$ is

$$
V_{\text {out }}=-2 V_{2}
$$

3.10. The $10^{\text {th }}$ Switching Pattern. In the tenth switching state pattern, the switches $S_{1}, T_{1}$, and $S_{y}$ are turned "on" and the switches $K_{1}, K_{2}, K_{3}, K_{4}$, and $S_{x}$ are turned "off," so the circuit diagram can be visualized as shown in Figure 12.

So $V_{\text {out }}$ is

$$
V_{\text {out }}=V_{1}+V_{2}
$$

3.11. The $11^{\text {th }}$ Switching Pattern. In the eleventh switching state pattern, the switches $S_{1}, T_{1}$, and $S_{x}$ are turned "on"

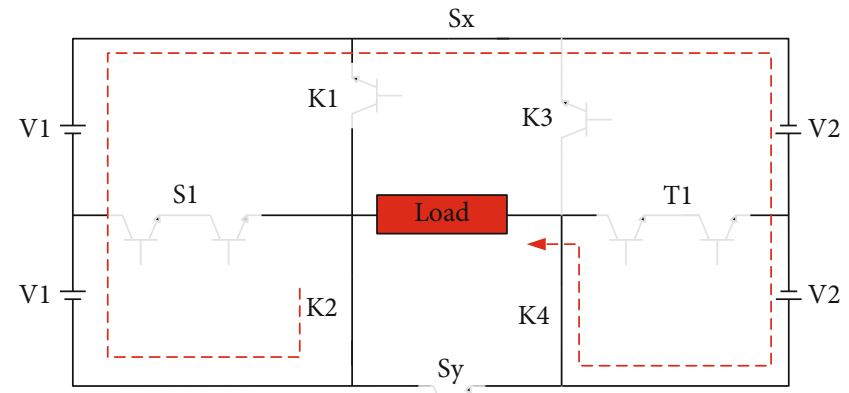

FIgURe 19: Current flow for the $17^{\text {th }}$ switching pattern.

\begin{tabular}{|c|c|c|c|c|c|c|c|c|c|}
\hline $\begin{array}{l}\text { Switch } \\
\text { pattern no. }\end{array}$ & $K_{1}$ & $K_{2}$ & $K_{3}$ & $K_{4}$ & $S_{1}$ & $T_{1}$ & $S_{x}$ & $S_{y}$ & $V_{\text {out }}$ equation \\
\hline 1 & 1 & 0 & 1 & 0 & 0 & 0 & 1 & 0 & 0 \\
\hline 2 & 0 & 0 & 0 & 1 & 1 & 0 & 0 & 1 & $V_{1}$ \\
\hline 3 & 0 & 0 & 1 & 0 & 1 & 0 & 1 & 0 & $-V_{1}$ \\
\hline 4 & 0 & 1 & 0 & 0 & 0 & 1 & 0 & 1 & $V_{2}$ \\
\hline 5 & 1 & 0 & 0 & 0 & 0 & 1 & 1 & 0 & $-V_{2}$ \\
\hline 6 & 1 & 0 & 0 & 1 & 0 & 0 & 0 & 1 & $2 V_{1}$ \\
\hline 7 & 0 & 1 & 1 & 0 & 0 & 0 & 1 & 0 & $-2 V_{1}$ \\
\hline 8 & 0 & 1 & 1 & 0 & 0 & 0 & 0 & 1 & $2 V_{2}$ \\
\hline 9 & 1 & 0 & 0 & 1 & 0 & 0 & 1 & 0 & $-2 V_{2}$ \\
\hline 10 & 0 & 0 & 0 & 0 & 1 & 1 & 0 & 1 & $V_{1}+V_{2}$ \\
\hline 11 & 0 & 0 & 0 & 0 & 1 & 1 & 1 & 0 & $-V_{1}-V_{2}$ \\
\hline 12 & 1 & 0 & 0 & 0 & 0 & 1 & 0 & 1 & $2 V_{1}+V_{2}$ \\
\hline 13 & 0 & 1 & 0 & 0 & 0 & 1 & 1 & 0 & $-2 V_{1}-V_{2}$ \\
\hline 14 & 0 & 0 & 1 & 0 & 1 & 0 & 0 & 1 & $V_{1}+2 V_{2}$ \\
\hline 15 & 0 & 0 & 0 & 1 & 1 & 0 & 1 & 0 & $-V_{1}-2 V_{2}$ \\
\hline 16 & 1 & 0 & 1 & 0 & 0 & 0 & 0 & 1 & $2 V_{1}+2 V_{2}$ \\
\hline 17 & 0 & 1 & 0 & 1 & 0 & 0 & 1 & 0 & $-2 V_{1}-V_{2}$ \\
\hline
\end{tabular}

TABLE 1: Switching states of a multilevel inverter.

and the switches $K_{1}, K_{2}, K_{3}, K_{4}$, and $S_{y}$ are kept "off," and the circuit path can be visualized in Figure 13.

So $V_{\text {out }}$ is

$$
V_{\text {out }}=-\left(V_{1}+V_{2}\right)
$$

3.12. The $12^{\text {th }}$ Switching Pattern. In the twelfth switching state pattern, the switches $K_{1}, T_{1}$, and $S_{y}$ are turned "on" and the switches $K_{2}, K_{3}, K_{4}, S_{1}$, and $S_{x}$ are kept "off," and the circuit path can be visualized in Figure 14.

So $V_{\text {out }}$ is
$V_{\text {out }}=2 V_{1}+V_{2}$. 


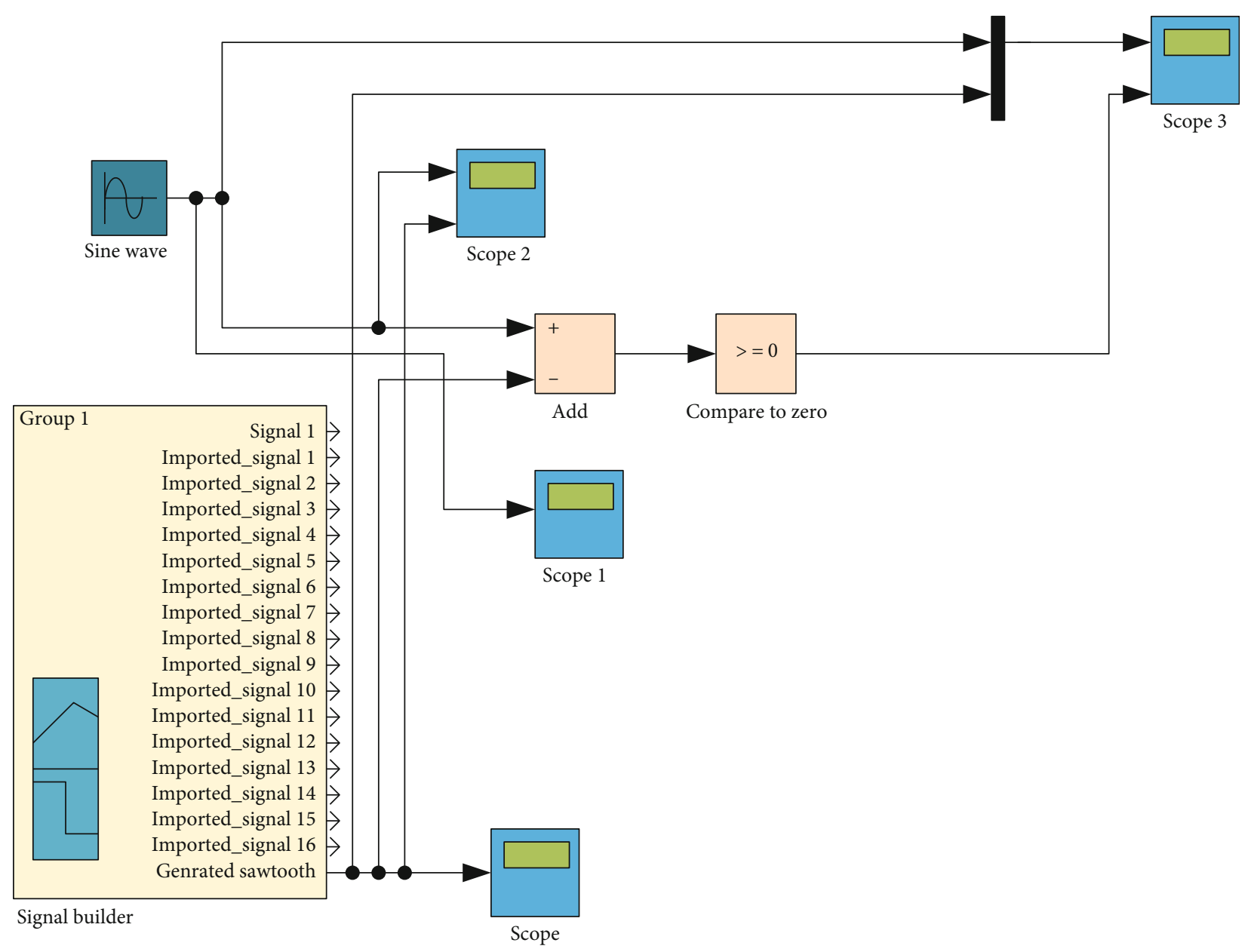

FIgURE 20: Circuit used for calculating switching sequence for $K_{1}$ switch.
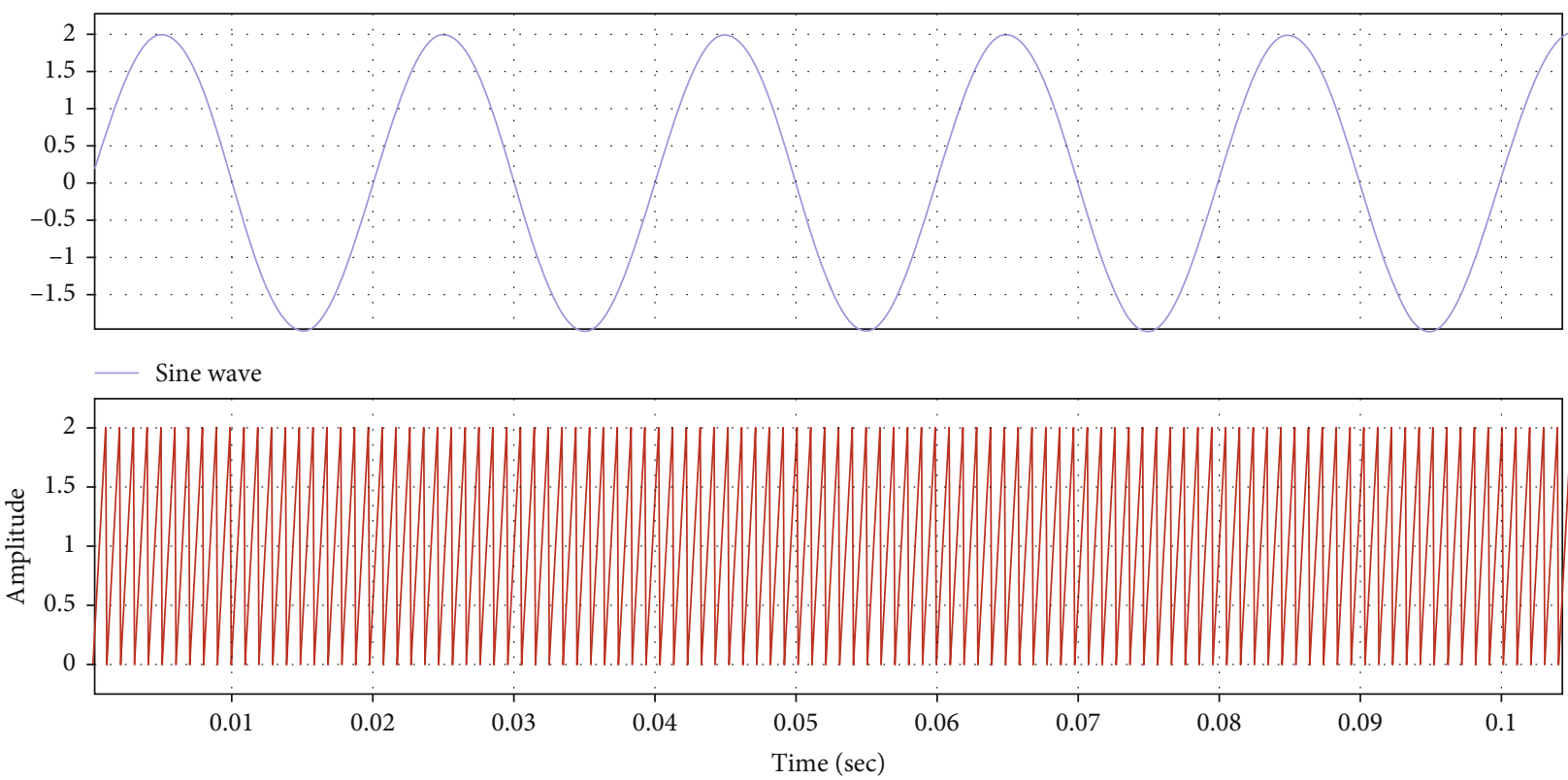

Signal builder/18

Figure 21: Sine wave and Saw tooth wave generated for calculating $K_{1}$ switch sequence. 


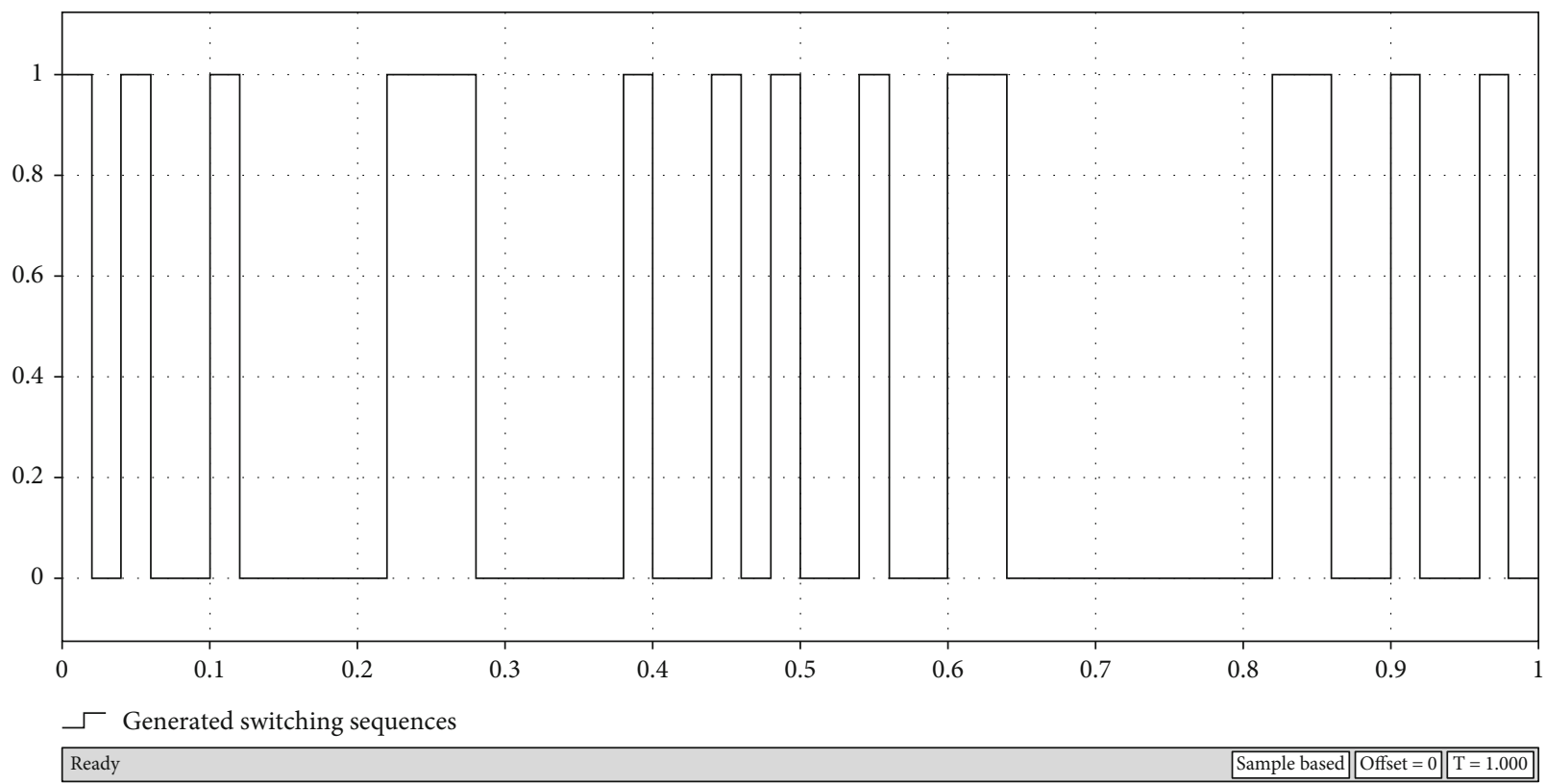

Figure 22: Generated pulses for the $K_{1}$ switch.

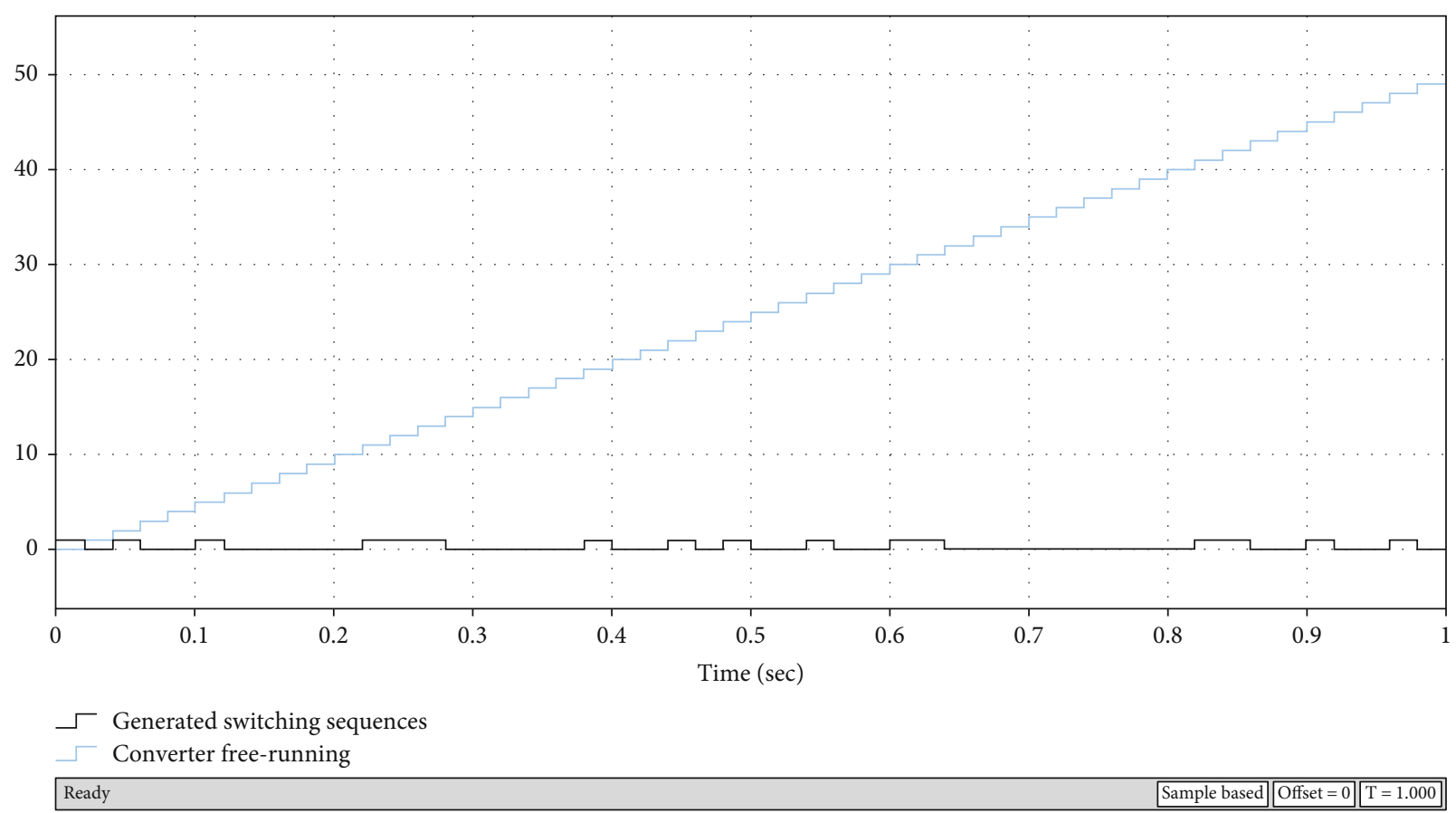

FIgURE 23: Pulse counter and generated switching sequences for the $K_{1}$ switch.

3.13. The $13^{\text {th }}$ Switching Pattern. In the thirteenth switching state pattern, the switches $T_{1}, K_{2}$, and $S_{x}$ are turned "on" and the switches $K_{1}, K_{3}, K_{4}, S_{1}$, and $S_{y}$ are kept "off," and the circuit path can be visualized in Figure 15.

So $V_{\text {out }}$ is
3.14. The $14^{\text {th }}$ Switching Pattern. In the fourteenth switching state pattern, the switches $S_{1}, K_{3}$, and $S_{y}$ are turned "on" and the switches $K_{1}, K_{2}, K_{4}, T_{1}$, and $S_{x}$ are turned "off," and the circuit path can be visualized in Figure 16.

So $V_{\text {out }}$ is

$$
V_{\text {out }}=-\left(2 V_{1}+V_{2}\right)
$$

$$
V_{\text {out }}=V_{1}+2 V_{2}
$$


3.15. The $15^{\text {th }}$ Switching Pattern. In the fifteenth switching state pattern, the switches $S_{1}, K_{4}$, and $S_{x}$ are turned "on" and the switches $K_{1}, K_{2}, K_{3}, T_{1}$, and $S_{y}$ are turned "off," and the circuit path can be visualized in Figure 17.

So $V_{\text {out }}$ is

$$
V_{\text {out }}=-\left(V_{1}+2 V_{2}\right)
$$

3.16. The $16^{\text {th }}$ Switching Pattern. In the sixteenth switching state pattern, the switches $K_{1}, K_{3}$, and $S_{y}$ are turned "on" and the switches $K_{2}, K_{4}, S_{1}, T_{1}$, and $S_{x}$ are kept "off," and the circuit path can be visualized in Figure 18.

So $V_{\text {out }}$ is

$$
V_{\text {out }}=2 V_{1}+2 V_{2}
$$

3.17. The $17^{\text {th }}$ Switching Pattern. In the seventeenth switching state pattern, the switches $K_{2}, K_{4}$, and $S_{x}$ are turned "on" and the switches $K_{1}, K_{3}, S_{1}, T_{1}$, and $S_{y}$ are kept "off," the circuit path can be visualized in Figure 19.

So $V_{\text {out }}$ is

$$
V_{\text {out }}=-2\left(\mathrm{~V}_{1}+\mathrm{V}_{2}\right)
$$

All the switching states and voltage equations calculated for different closed-loop paths of the schematic in Figure 2 are reproduced in Table 1.

\section{Voltage Stress and Switching Loss Estimation}

To generate the gate pulses based on the switching sequence, a carrier-based adjustment technique is used. As all the switches turns on and off thousand times in a second, there is switching power loss in each switching device due to the on state current and off state voltage. In order to estimate the switching losses, the loss in switch $K_{1}$ is calculated theoretically as follows:

$$
\begin{aligned}
V_{1} & =25 \text { volts, } \\
V_{2} & =75 \text { volts, } \\
V_{O} & =200 \mathrm{rms}, \\
F_{\mathrm{SW}} & =1 \mathrm{Khz}, \\
I_{O} & =5 \mathrm{~A} .
\end{aligned}
$$

Voltage stress across switch $K_{1}$ is given as

\begin{tabular}{|c|c|c|c|c|c|c|c|}
\hline$K_{1}$ & $K_{2}$ & $K_{3}$ & $K_{4}$ & $S_{1}$ & $T_{1}$ & $S_{X}$ & $S_{y}$ \\
\hline 1 & 0 & 1 & 0 & 0 & 0 & 1 & 0 \\
\hline 0 & 0 & 0 & 1 & 1 & 0 & 0 & 1 \\
\hline 1 & 0 & 0 & 1 & 0 & 0 & 0 & 1 \\
\hline 0 & 1 & 0 & 0 & 0 & 1 & 0 & 1 \\
\hline 0 & 0 & 0 & 0 & 1 & 1 & 0 & 1 \\
\hline 1 & 0 & 0 & 0 & 0 & 1 & 0 & 1 \\
\hline 0 & 1 & 1 & 0 & 0 & 0 & 0 & 1 \\
\hline 0 & 1 & 1 & 0 & 0 & 0 & 0 & 1 \\
\hline 0 & 0 & 1 & 0 & 1 & 0 & 0 & 1 \\
\hline 0 & 0 & 1 & 0 & 1 & 0 & 0 & 1 \\
\hline 0 & 0 & 1 & 0 & 1 & 0 & 0 & 1 \\
\hline 1 & 0 & 1 & 0 & 0 & 0 & 0 & 1 \\
\hline 1 & 0 & 1 & 0 & 0 & 0 & 0 & 1 \\
\hline 1 & 0 & 1 & 0 & 0 & 0 & 0 & 1 \\
\hline 0 & 0 & 1 & 0 & 1 & 0 & 0 & 1 \\
\hline 0 & 0 & 1 & 0 & 1 & 0 & 0 & 1 \\
\hline 0 & 0 & 1 & 0 & 1 & 0 & 0 & 1 \\
\hline 0 & 1 & 1 & 0 & 0 & 0 & 0 & 1 \\
\hline 0 & 0 & 1 & 0 & 0 & 0 & 0 & 1 \\
\hline 1 & 0 & 0 & 0 & 0 & 1 & 0 & 1 \\
\hline 0 & 1 & 0 & 0 & 1 & 1 & 0 & 1 \\
\hline 0 & 0 & 0 & 0 & 0 & 1 & 0 & 1 \\
\hline 1 & 0 & 0 & 1 & 0 & 0 & 0 & 1 \\
\hline 0 & 0 & 0 & 1 & 1 & 0 & 0 & 1 \\
\hline 1 & 0 & 1 & 0 & 0 & 0 & 1 & 0 \\
\hline 0 & 1 & 1 & 0 & 1 & 0 & 1 & 0 \\
\hline 0 & 0 & 1 & 0 & 0 & 0 & 1 & 0 \\
\hline 1 & 0 & 0 & 0 & 0 & 1 & 1 & 0 \\
\hline 0 & 1 & 0 & 0 & 1 & 1 & 1 & 0 \\
\hline 0 & 0 & 0 & 1 & 0 & 1 & 1 & 0 \\
\hline 1 & 0 & 0 & 1 & 0 & 0 & 1 & 0 \\
\hline 1 & 0 & 0 & 1 & 0 & 0 & 1 & 0 \\
\hline 0 & 0 & 0 & 1 & 1 & 0 & 1 & 0 \\
\hline 0 & 0 & 0 & 1 & 1 & 0 & 1 & 0 \\
\hline 0 & 1 & 0 & 1 & 1 & 0 & 1 & 0 \\
\hline 0 & 1 & 0 & 1 & 0 & 0 & 1 & 0 \\
\hline 0 & 0 & 0 & 1 & 0 & 0 & 1 & 0 \\
\hline 0 & 0 & 0 & 1 & 0 & 0 & 1 & 0 \\
\hline 0 & 0 & 0 & 1 & 1 & 0 & 1 & 0 \\
\hline 0 & 0 & 0 & 1 & 1 & 0 & 1 & 0 \\
\hline 0 & 0 & 0 & 1 & 1 & 0 & 1 & 0 \\
\hline 1 & 0 & 0 & 1 & 0 & 0 & 1 & 0 \\
\hline 1 & 0 & 0 & 1 & 0 & 0 & 1 & 0 \\
\hline 0 & 1 & 0 & 0 & 0 & 1 & 1 & 0 \\
\hline
\end{tabular}

$$
V_{K_{1}(\text { Stress })}=V_{1}=25 \text { volts. }
$$

Current stress through switch $K_{1}$ is given as

$$
I_{K_{1} \text { (Stress) }}=5 \text { amperes. }
$$

Switching power loss across switch $K_{1}$ is given as
TABLE 2: Switching sequence of an MLI.

$$
P_{K_{1}(\mathrm{SW})}=\frac{1}{6}\left[V_{K_{1}(\text { Stress })} * I_{K_{1}(\text { Stress })} * F_{\mathrm{SW}}\right] *\left[t r+t_{f}\right] .
$$

$\operatorname{tr}$ and $t_{f}$ have been taken 20 nanoseconds for a typical $N$-channel Mosfet. 


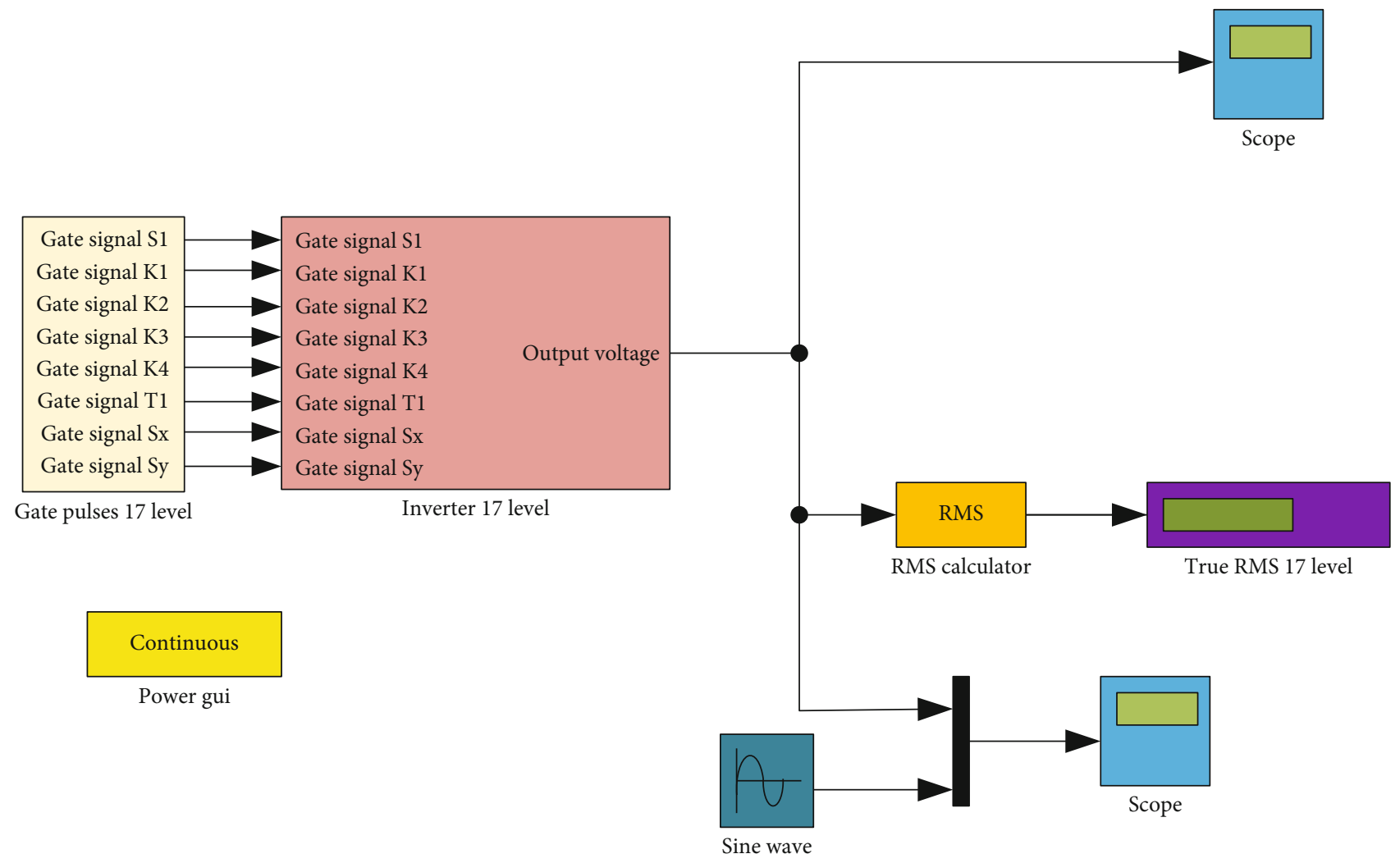

Figure 24: 17-level multilevel inverter.

TABLE 3: Circuit component values used in simulation and experimental setup.

\begin{tabular}{lcc}
\hline S. no. & Component & Value \\
\hline 1 & Vin & $220 \mathrm{volts}$ \\
2 & $\mathrm{Lf}$ & $5 \mathrm{mH}$ \\
3 & $\mathrm{Lb}$ & $200 \mathrm{uH}$ \\
4 & C1\&C2 & $330 \mathrm{nF}$ \\
5 & Cbus & $10 \mathrm{nF}$ \\
6 & Lm & $100 \mathrm{uH}$ \\
7 & Cr & $30 \mathrm{nF}$ \\
8 & Lr & $20 \mathrm{uH}$ \\
9 & Co & $10 \mathrm{nF}$ \\
10 & Switching frequency & $10 \mathrm{~Hz}$ \\
\hline
\end{tabular}

$$
\begin{aligned}
P_{K_{1}(\mathrm{SW})} & =\frac{1}{6}[25 * 5 * 1000][20 * 10-9+20 * 10-9] \\
P_{K_{1}(\mathrm{SW})} & =0.417 \text { milliwatts. }
\end{aligned}
$$

Similarly, the switching losses in other switches can be calculated.
TABLE 4: Output voltage values.

\begin{tabular}{lcc}
\hline S. no & $V_{\text {out }}$ equation & $V_{\text {out }}$ value $(\mathrm{V})$ \\
\hline 1 & 0 & 0 \\
2 & $V_{1}$ & 25 \\
3 & $-V_{1}$ & -25 \\
4 & $V_{2}$ & 75 \\
5 & $-V_{2}$ & -75 \\
6 & $2 V_{1}$ & 50 \\
7 & $-2 V_{1}$ & -50 \\
8 & $2 V_{2}$ & 150 \\
9 & $-2 V_{2}$ & -150 \\
10 & $V_{1}+V_{2}$ & 100 \\
11 & $-\left(V_{1}+V_{2}\right)$ & -100 \\
12 & $2 V_{1}+V_{2}$ & 125 \\
13 & $-\left(2 V_{1}+V_{2}\right)$ & -125 \\
14 & $V_{1}+2 V_{2}$ & 175 \\
15 & $-\left(V_{1}+2 V_{2}\right)$ & -175 \\
16 & $2 V_{1}+2 V_{2}$ & 200 \\
\hline
\end{tabular}

\section{Generation of Gate Pulses for Switching Operation}

To generate the gate pulses based on the switching sequence, a carrier-based adjustment technique is used since it is useful 


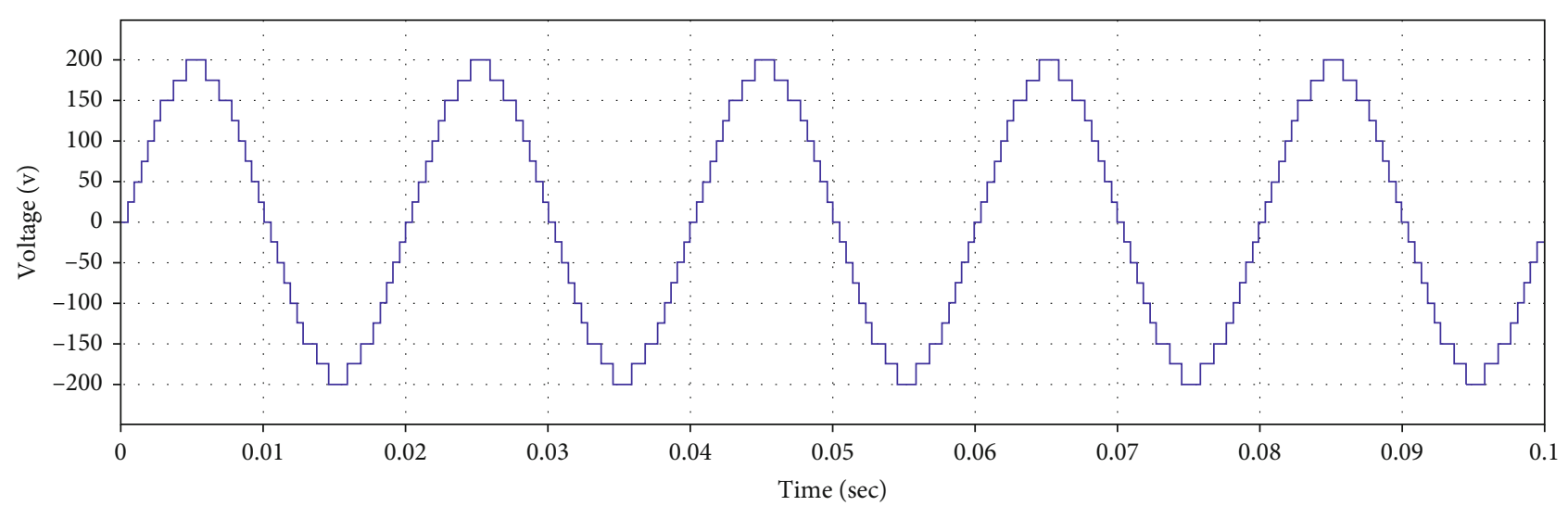

17 level inverter

FIGURE 25: Single-phase 17-level MLI with $t=0.1$.

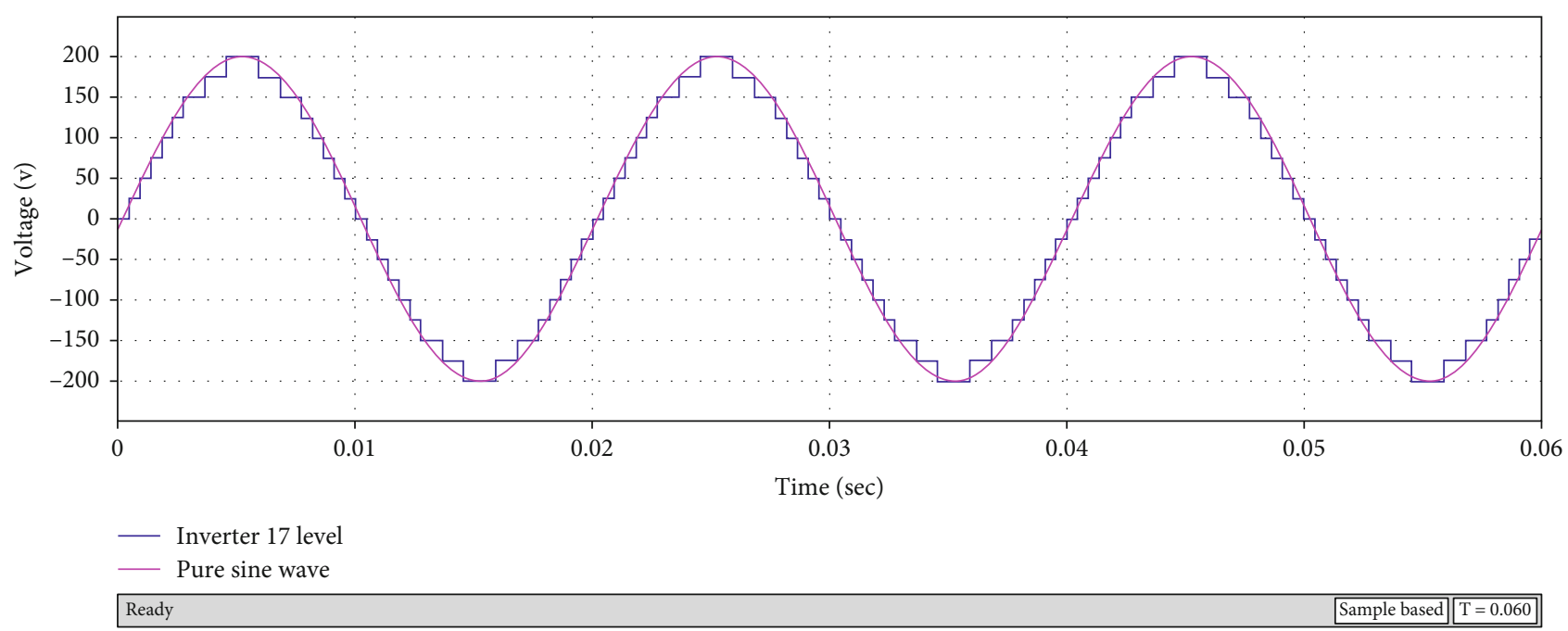

Figure 26: Single-phase 17-level MLI with $t=0.06$.

in minimizing THD. An example of the implementation of this technique in MATLAB/Simulink is shown in Figure 20, where switching sequence for switch $K_{1}$ is generated using a constant SPWM technique. Sine wave and sawtooth waveforms (see Figure 21) are used to generate the switching sequence for switch $K_{1}$ (see Figure 22).

Figure 20 shows the circuit, used for calculating the switching sequence of pulses, for the $K_{1}$ switch.

Because of playing out the above SPWM method, pulses produced for the $K_{1}$ switch are shown in Figure 22 .

Figure 22 demonstrates the pulses that are obtained by SPWM activity for the further task of the $K_{1}$ switch. To decide on the on and off states of a switch, a counter is used. For example, the switching sequence generation is demonstrated for the switch $K_{1}$ as shown in Figure 23. It can be noted that there are 48 states as calculated by the counter that represents the of and off states of the switching sequence for switch $K_{1}$. Similarly, switching sequences can be computed for all the switches.
Table 2 demonstrates the total 48 switching sequence for all the eight switches utilized in Figure 2.

\section{Results and Discussion}

The 17-level multilevel inverter with switches and DC sources was implemented in 203 MATLAB/Simulink as shown in Figure 24. Various values used for generating the simulation results as well as the experimental results are given in Table 3.

6.1. Theoretical Results. For the proposed MLI, a voltage in a ratio of $1: 3$ needs to be selected. There are two DC sources $V_{1}$ and $V_{2}$ and overall four DC sources. These DC sources can be replaced by photovoltaic panels such that $V_{1}=25 \mathrm{~V}$ and $V_{2}=75 \mathrm{~V}$. It means that $V_{2}$ is three times $V_{1}$. Results are obtained for a grid voltage of 200 volts at a frequency of $50 \mathrm{~Hz}$. The switching frequency is $1 \mathrm{kHz}$. By putting the 


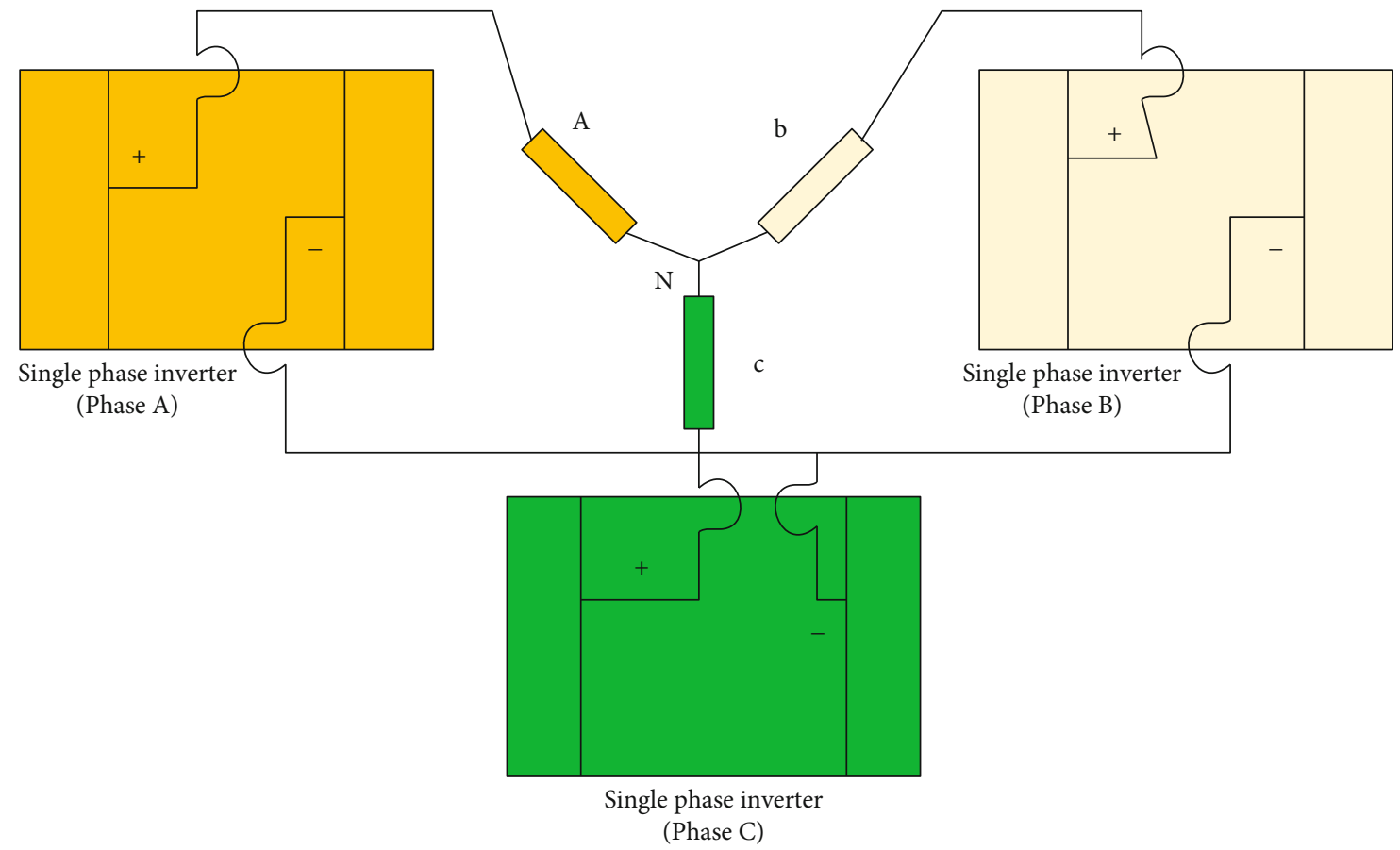

FIgURE 27: Three-phase inverter connection.

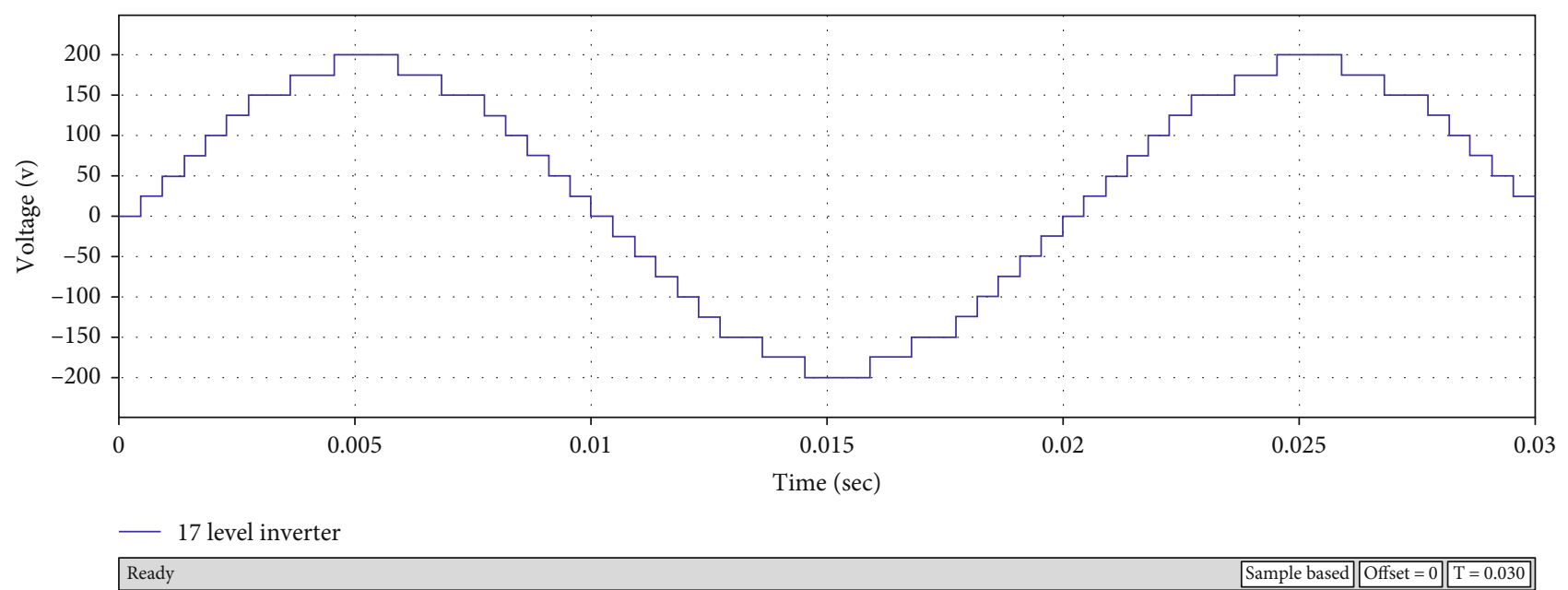

FIgURE 28: 17-level MLI with $t=0.03$ for phase a.

estimations of $V_{1}$ and $V_{2}$ in Table 1, we get the accompanying results in Table 4.

6.2. Simulation Results. The simulation setup is represented in Figure 24. Each switch is modeled by an IGBT in the simulation. The simulated waveforms are in the accompanying figures. The simulation results confirm the expected results as the THD is brought down to $3.52 \%$.

6.2.1. Single-Phase MLI Simulations. The resulting voltage waveform of single-phase MLI is depicted in Figures 25 and 26; it is compared with a clean sinusoidal waveform of the same frequency to get a good visualization of the reduction in THD.
6.2.2. Three-Phase MLI Simulations. In three-phase MLI, the three phases, namely, phase "a," phase "b," and phase " $c$ " are depicted in Figure 27. For phase "b," a 120-degree phase shift is needed w.r.t phase "a." Also for phase "c," another 120-degree phase move w.r.t phase "a" or 120degree phase shift w.r.t phase " $b$ " is needed. Since there are 48 switching patterns, these need to be accommodated in 360 degrees cycle, so 


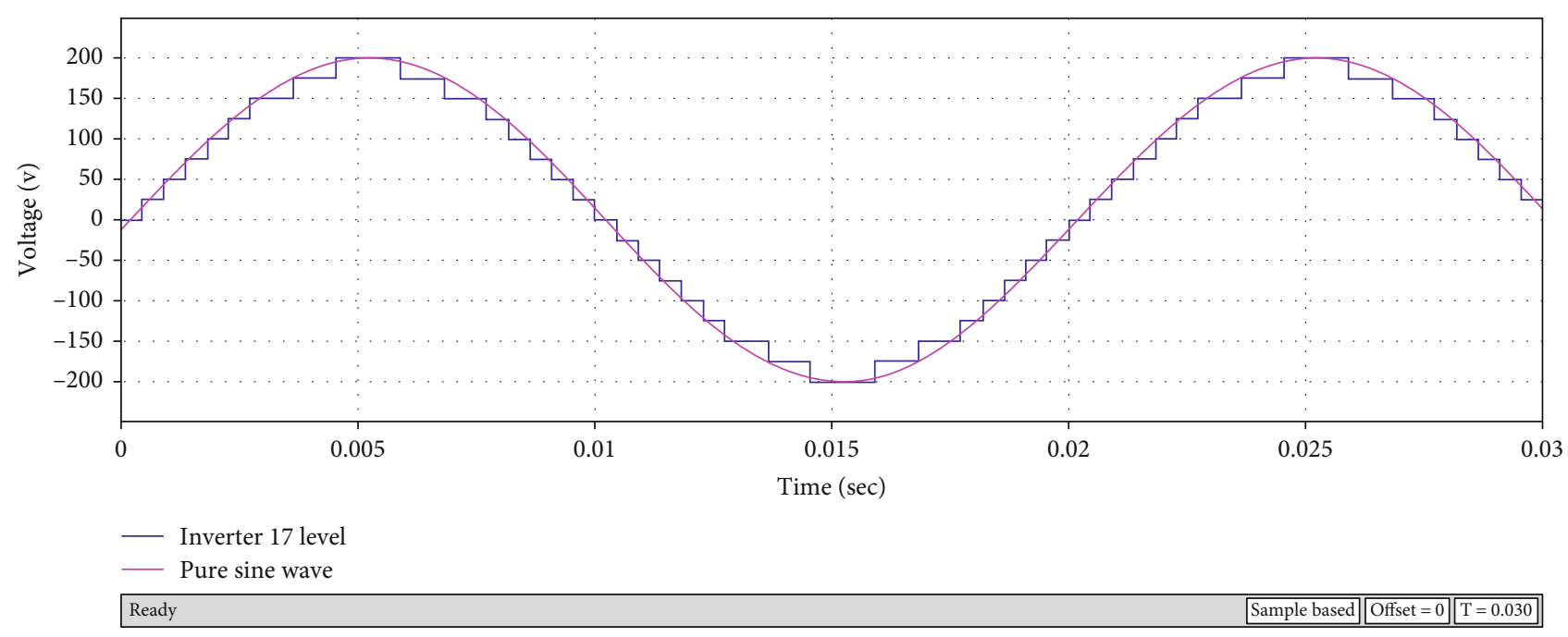

FIgURE 29: 17-level MLI with $t=0.03$ for phase a and compared with sine wave.

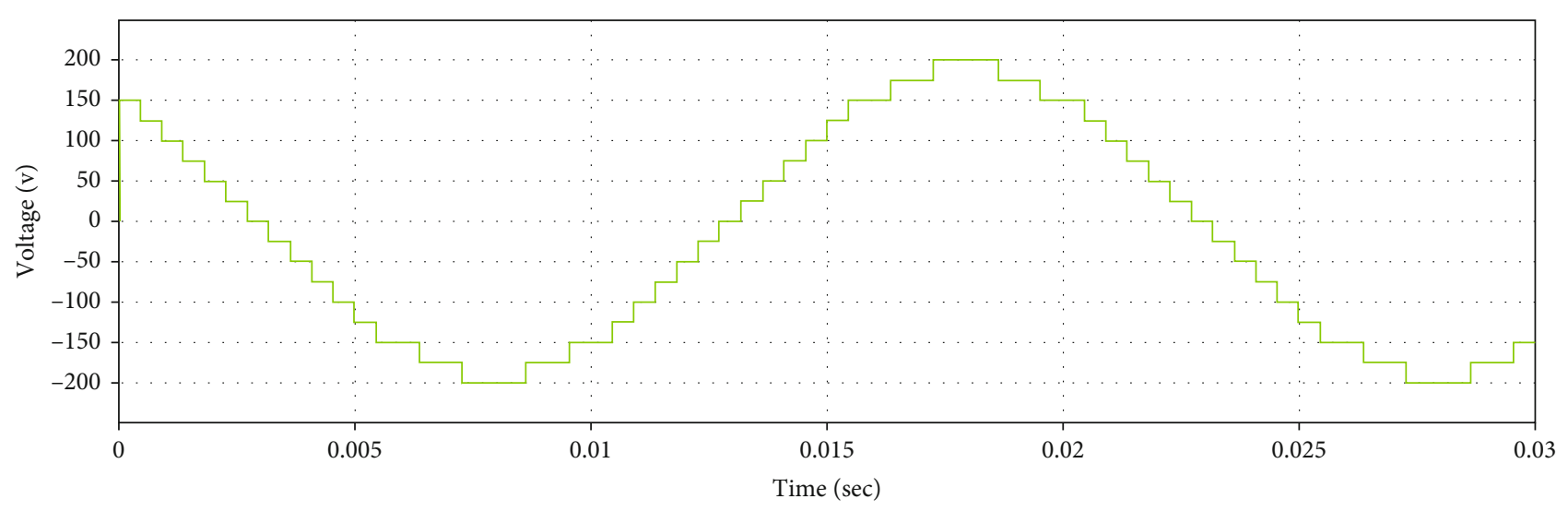

_ Inverter 17 level with -127.5 phase shift

\begin{tabular}{lr}
\hline Ready & Sample based $T=0.030$ \\
\hline
\end{tabular}

FIGURE 30: 17-level MLI with $t=0.03$ for phase $\mathrm{b}$.

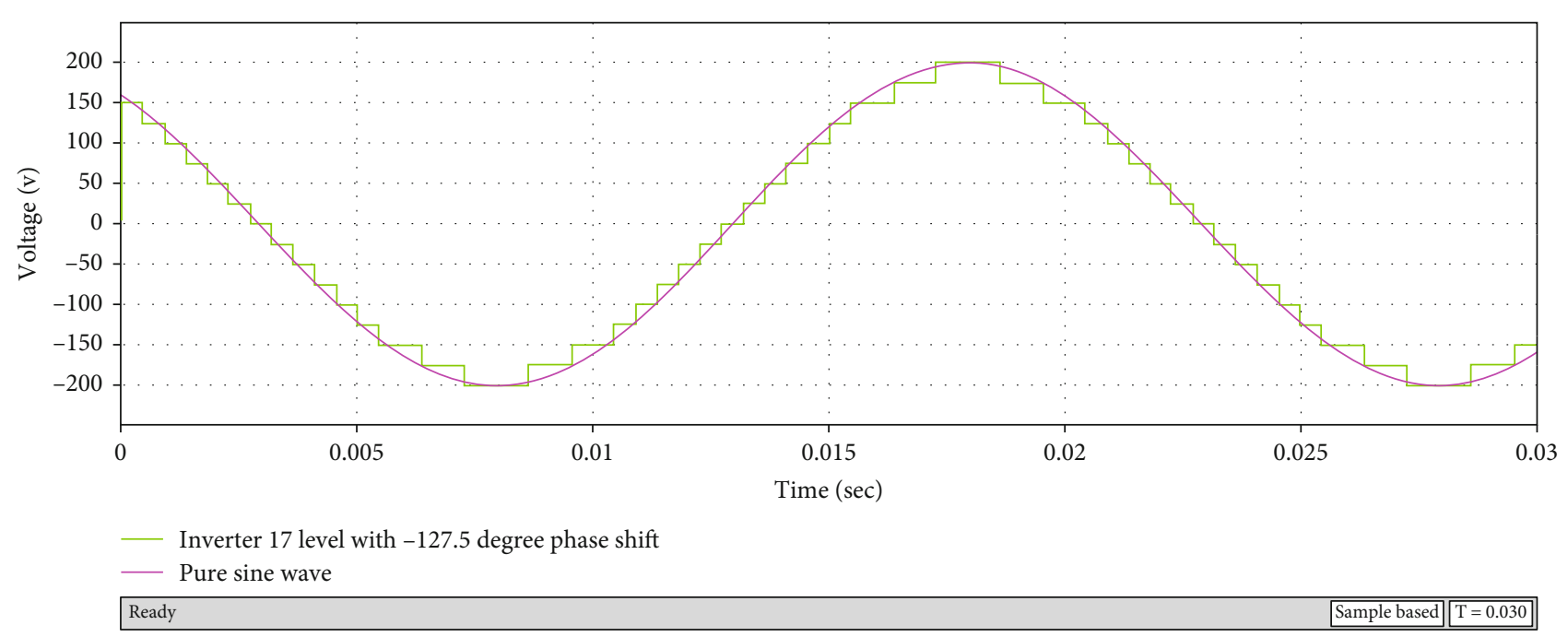

Figure 31: 17-level MLI with $t=0.03$ for phase $\mathrm{b}$ and compared with sine wave. 


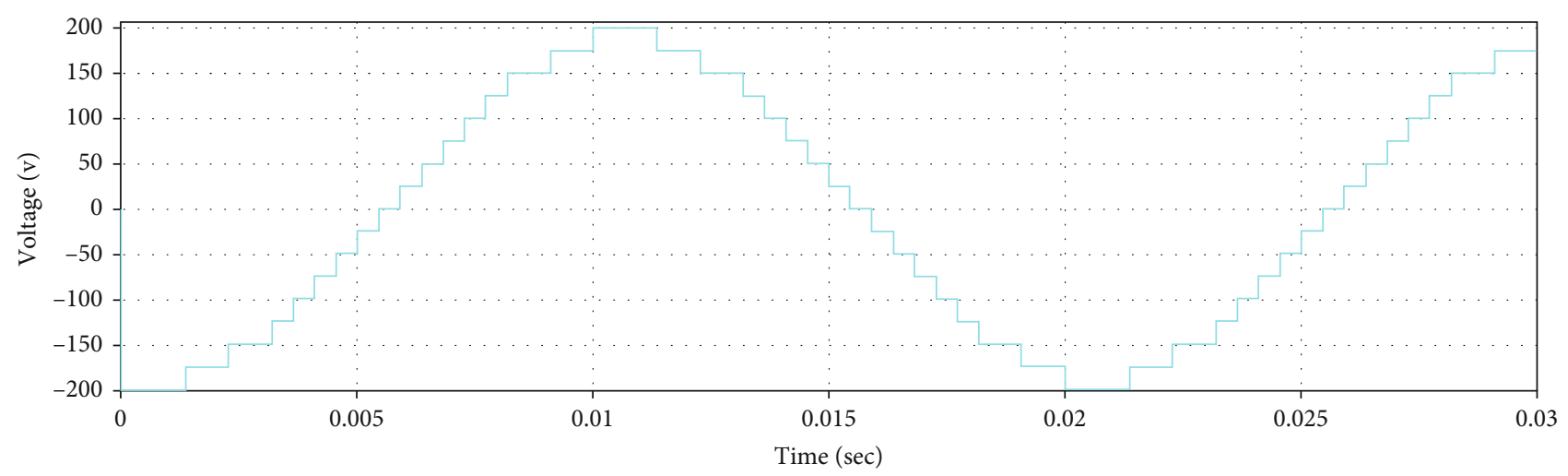

Inverter 17 level with 127.5 degree phase shift

Figure 32: 17-level MLI with $t=0.03$ for phase $\mathrm{c}$.

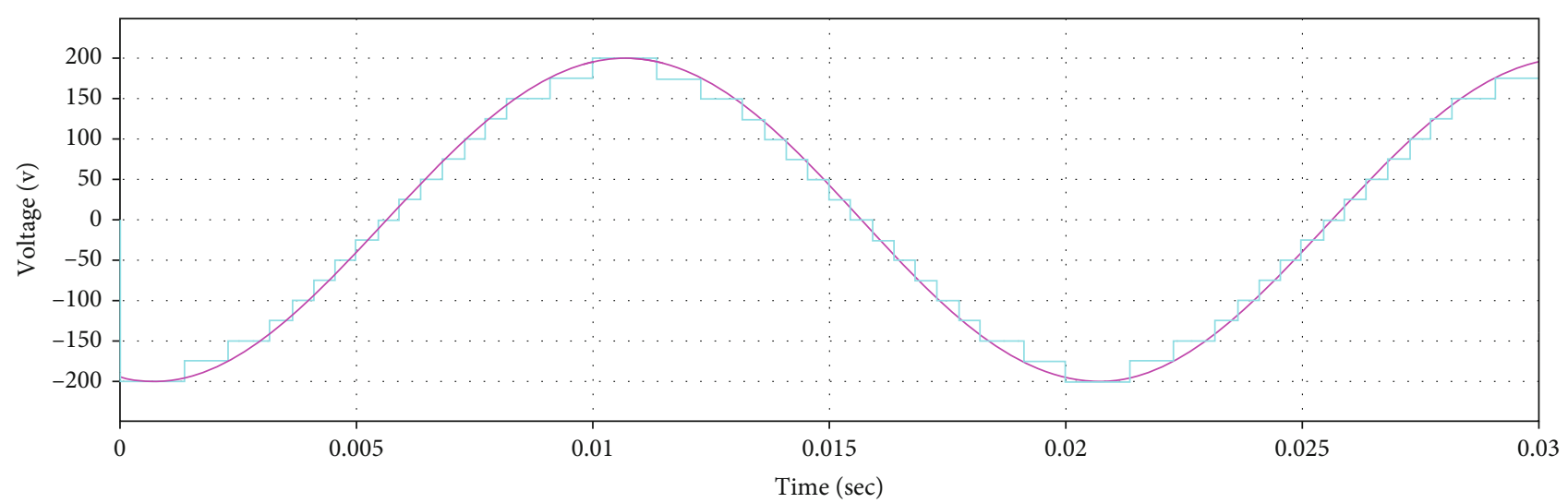

- Inverter 17 level with 127.5 degree phase shift

- Pure sine wave

\begin{tabular}{lr}
\hline Ready & Sample based $T=0.030$ \\
\hline
\end{tabular}

FIGURE 33: 17-level MLI with $t=0.03$ for phase $\mathrm{c}$ and compared with sine wave.

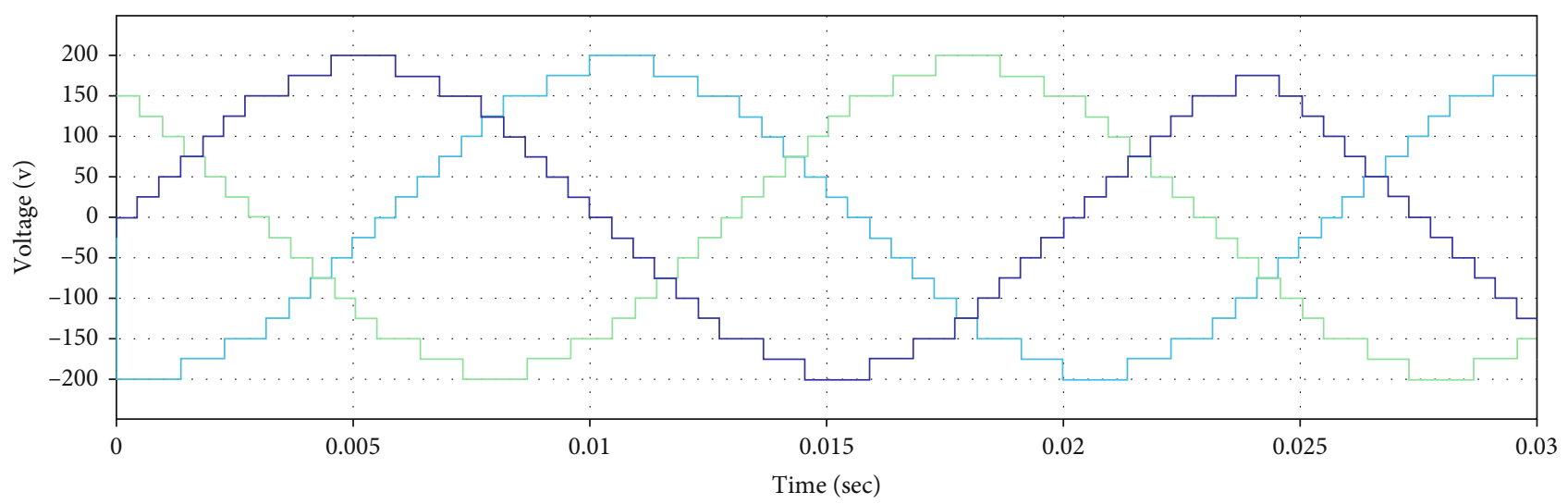

— Inverter 17 level phase a

Inverter 17 level phase b

- Inverter 17 level phase c

Figure 34: 3-phase 17-level MLI with $t=0.03$. 


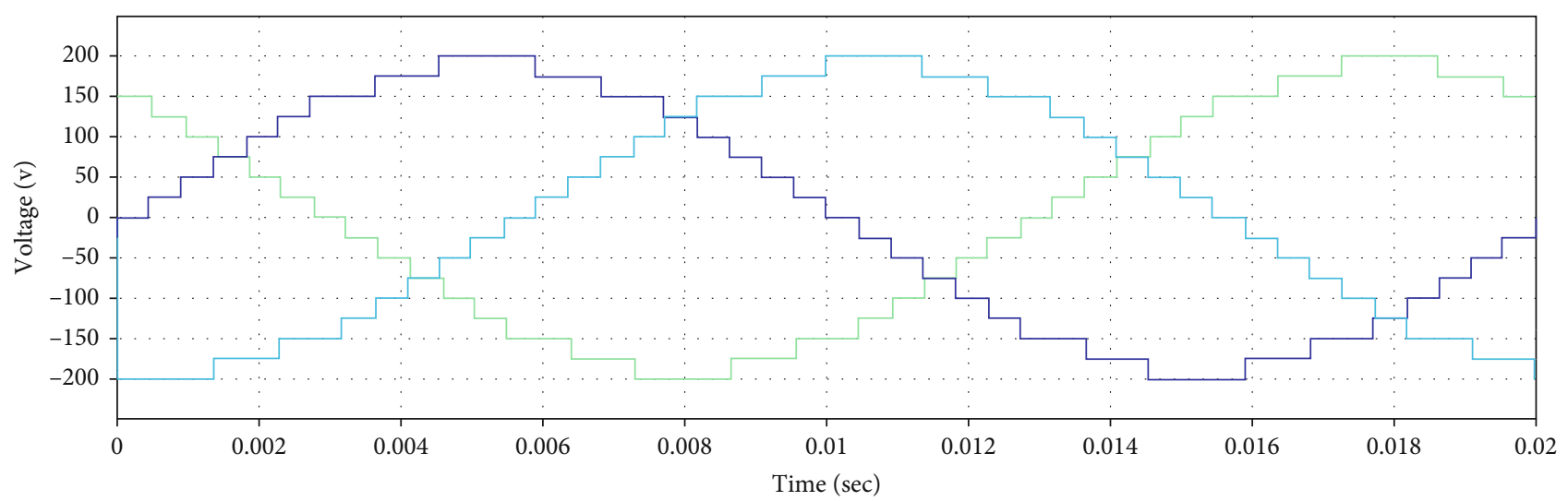

Inverter 17 level phase a
Inverter 17 level phase b
Inverter 17 level phase c

FIgURE 35: 3-phase MLI output with $t=0.02$.

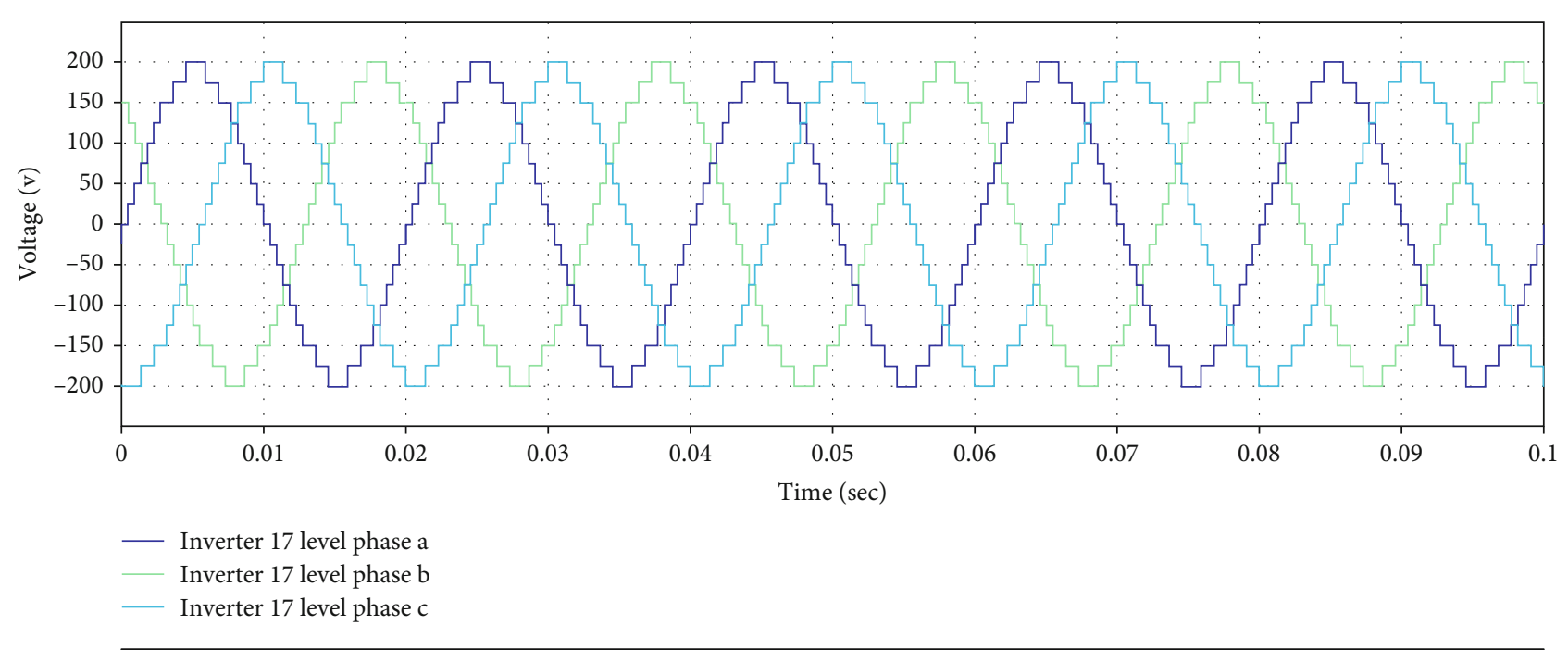

FIGURE 36: 3-phase MLI output with $t=0.1$.

For 120-degree phase move,

$$
\text { Bits shifts }=120 / 7.5=16 \text {. }
$$

Therefore, it should be noted that phase "a" will begin at the first switching pattern and phase " $b$ " at the $17^{\text {th }}$ switching pattern and lastly phase "c" will begin at the $33^{\text {rd }}$ switching pattern and then the cycle repeats itself.

(1)Phase a Results. Figures 28 and 29 show simulation waveforms of phase a for a time duration of 30 milliseconds.

(2)Phase $b$ Results. Figures 30 and 31 show simulation waveforms of phase $b$ for a time duration 30 of milliseconds.
(3)Phase c Results. Figures 32 and 33 show simulation waveforms of phase $\mathrm{c}$ for a time duration 30 of milliseconds.

(4)3-Phase Results. Figures 34-37 show simulation waveforms for all three phases of proposed MLI.

6.3. Fast Fourier Transform Analysis for THD. FFT investigation is done in Simulink/MATLAB to locate the total harmonic distortion on the frequency spectrum (see Figures 38 and 39). Total harmonic distortion is a helpful procedure to break down any nonlinear conduct of a framework, which is normally done with the help of fast Fourier transform (FFT). The measured signal is changed from the time domain into the frequency domain (see Figure 39). The changed information can be shown in an FFT spectrum in which the response signal's magnitude is plotted versus the frequency. Figure 39 shows the FFT spectrum of a 17-level MLI. 

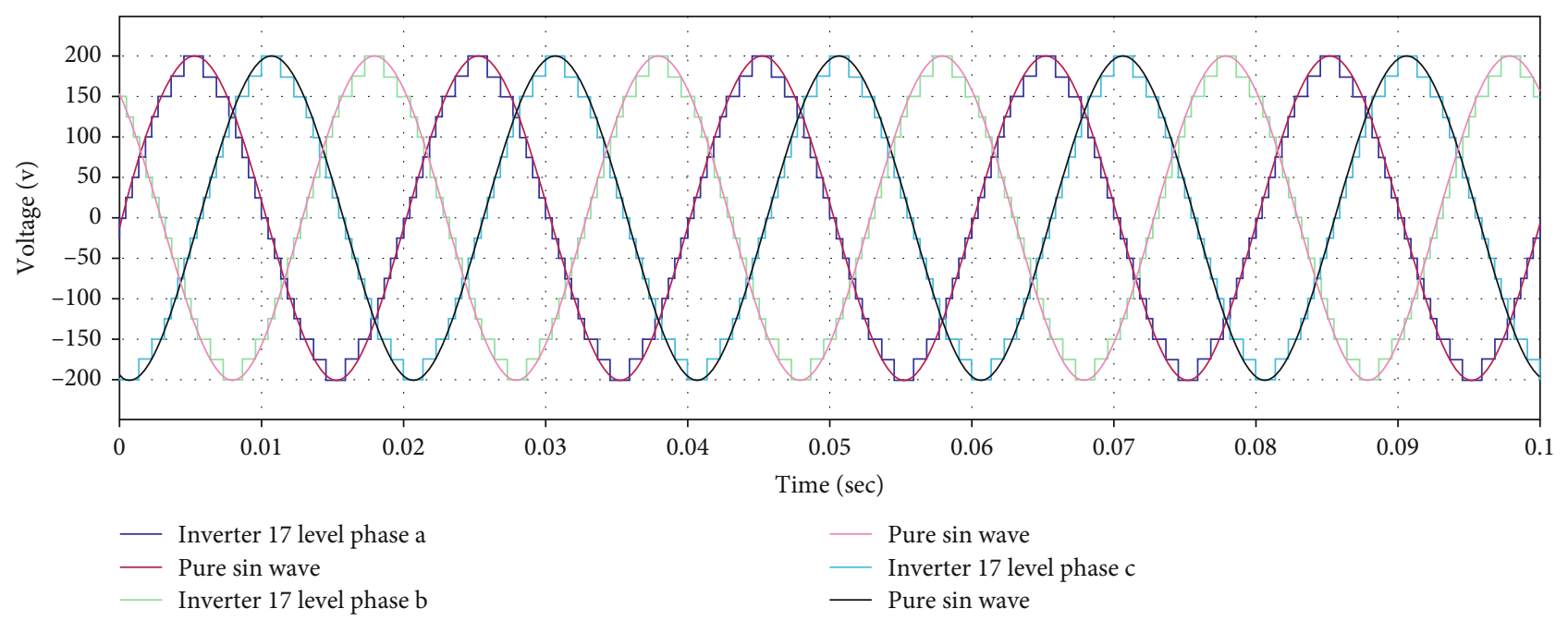

- Pure sin wave

_ Inverter 17 level phase c

- Inverter 17 level phase b

— Pure sin wave

Figure 37: 3 -phase MLI output with $t=0.1$ and compared with sine wave.

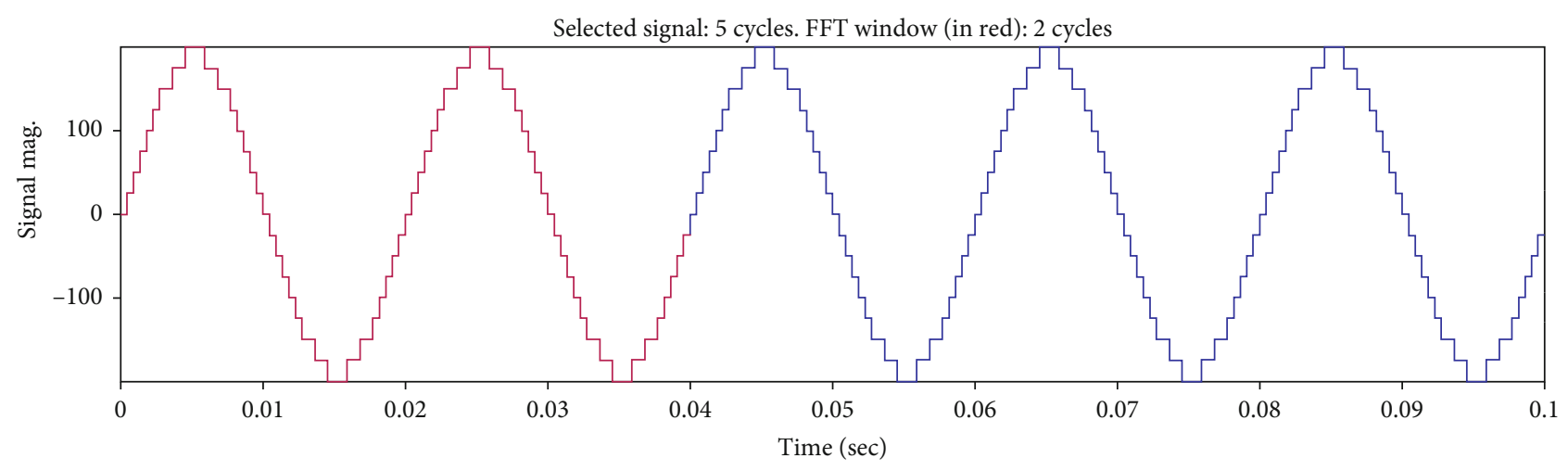

Figure 38: Input MLI signal.

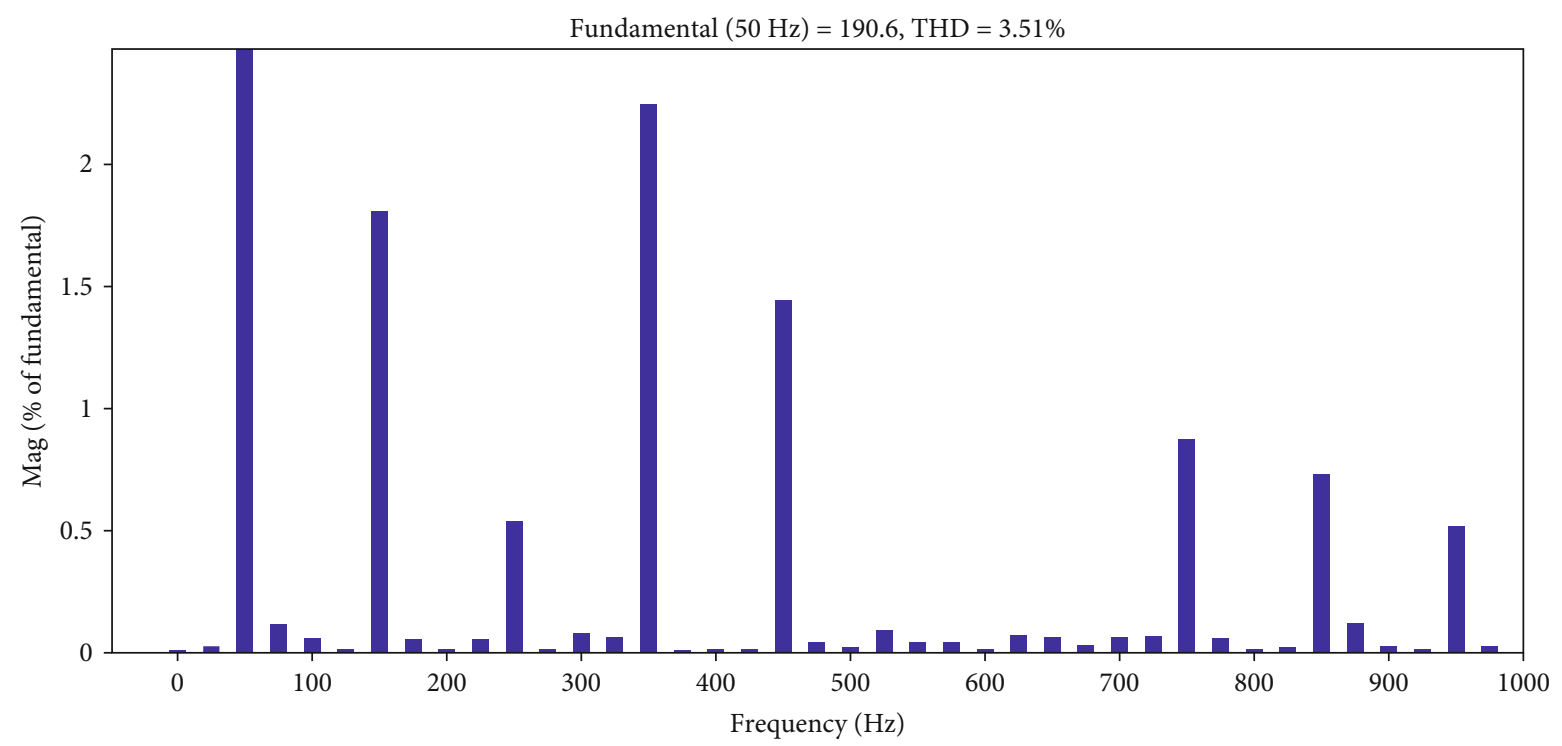

FIgURE 39: FFT spectrum of a 17-level MLI. 
TABLE 5: Harmonic vs. amplitude.

\begin{tabular}{lc}
\hline Harmonic no. & Amplitude $(\mathrm{V})$ \\
\hline 1 & 100 \\
3 & 1.7 \\
5 & 0.5 \\
7 & 2.3 \\
9 & 1.4 \\
11 & 0.1 \\
13 & 0.01 \\
15 & 0.7 \\
17 & 0.7 \\
19 & 0.5 \\
\hline
\end{tabular}

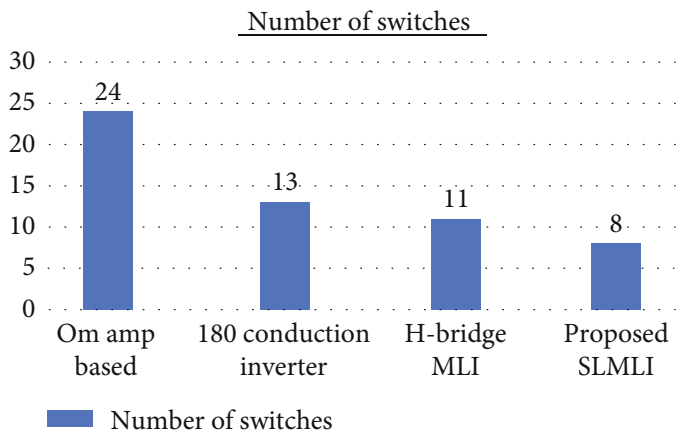

FIGURE 40: Comparison between numbers of switches.

We record the harmonics up till the $19^{\text {th }}$ harmonics, and we ignore the values after that because those values were too low and almost near to zero. The amplitude of each harmonic is shown in Table 5.

We plugged the values in the THD equation to calculate THD as follows:

$$
\begin{aligned}
& \mathrm{THD}=\frac{\sqrt{0.1^{2}+1.7^{2}+0.5^{2}+2.3^{2}+1.4^{2}+0.1^{2}+0.01^{2}+0.7^{2}+0.7^{2}+0.5^{2}}}{100}, \\
& \mathrm{THD}=\frac{\sqrt{0.01+2.89+0.25+5.29+1.96+0.01+0.0001+0.49+0.49+0.25}}{100}, \\
& \mathrm{THD}=\frac{\sqrt{11.6401}}{100}, \\
& \mathrm{THD}=\frac{3.522 * 100}{100}, \\
& \mathrm{THD}=3.52 \% .
\end{aligned}
$$

6.4. Comparison with Other Topologies. A comparison between the number of switches (see Figure 40), number of voltage levels (see Figure 41), and THD (see Figure 42) was conducted between different multilevel inverters and the proposed multilevel inverter. The proposed 17-level MLI uses the SPWM technique for generating the gate signals/pulses. This inverter uses less number of switches, i.e., 8, and generates a maximum number of voltage levels. It also shows a low THD of $3.52 \%$. The THD, where operational amplifier (Op-Amp) circuits were used for pulse generation,

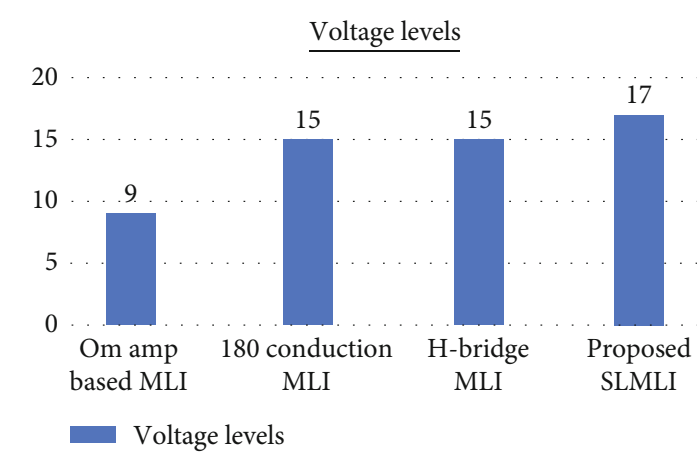

FIgURE 41: Comparison between numbers of voltage levels.

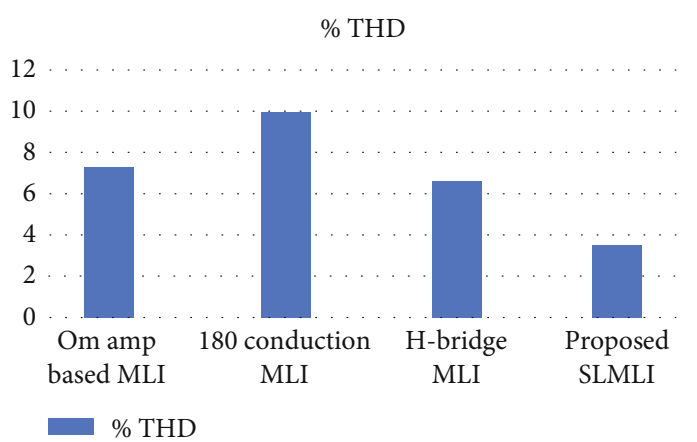

Figure 42: Comparison of \%THD.

turns out to be $7.3 \%$ whereas $180^{\circ}$ conduction MLI had 9.93\% THD and H-Bridge MLI had 6.63\% THD. Another multilevel inverter that uses the space vector modulation technique for generating pulses using switch ladder topology offers $6.1 \%$ THD.

From the above discussions, it is clear that the proposed MLI is superior to conventional MLI's in context of THD, number of switching devices, and voltage levels. The main limitation of proposed MLI is the bad regulation of output voltage and complexity in control of active switches.

\section{Conclusions}

In this paper, a modified form of a multilevel inverter has been successfully designed for high-power applications. The proposed topology has fewer switches due to which the cost is less. The proposed MLI solution does not require any filter at the output and produces less amount of THD. A thorough inquiry and scrutiny are carried out, and overall switching sequences have been evaluated for the proposed MLI. The THD of the system is $3.5 \%$, and also, there is low voltage stress across the switches and the output is a smooth sinusoidal AC. By setting tailored quality metrics, a theoretical comparison is carried out for the proposed MLI and the conventional MLI's. The results reflect that the proposed MLI has surpassed the conventional MLI in terms of performance, reduced components, and low total harmonic distortion. The theoretical results have been verified by simulation results in MATLAB/Simulink. The results of the simulations align with the theoretical implications. Due to low 
THD, the proposed MLI is a well-anticipated candidate for high-voltage/high-power applications. Considering the literature study done upon the MLI, it was seen that the main issue was concerned with the increased components as well as high THD. All of those parameters were improved by using the proposed topology. To reduce more components like DC sources, two capacitors can be used with only one DC source instead of two in the proposed MLI.

\section{Data Availability}

All relevant data and its supporting information files are included within the manuscript.

\section{Conflicts of Interest}

The authors declare that they have no conflicts of interest.

\section{References}

[1] M. Z. Malik, A. Ali, G. S. Kaloi, A. M. Soomro, M. H. Baloch, and S. T. Chauhdary, "Integration of renewable energy project: a technical proposal for rural electrification to local communities," IEEE Access, vol. 8, pp. 91448-91467, 2020.

[2] F. Akar, Y. Tavlasoglu, E. Ugur, B. Vural, and I. Aksoy, "A bidirectional nonisolated multi-input DC-DC converter for hybrid energy storage systems in electric vehicles," IEEE Transactions on Vehicular Technology, vol. 65, no. 10, pp. 7944-7955, 2015.

[3] I.-M. Pop-Calimanu, S. Lica, S. Popescu, D. Lascu, I. Lie, and R. Mirsu, "A new hybrid inductor-based boost DC-DC converter suitable for applications in photovoltaic systems," Energies, vol. 12, no. 2, p. 252, 2019.

[4] M. Z. Malik, A. Ali, and D. Kumar, "A two cascaded boost converter with high voltage gain module," International Journal of Computer and Electrical Engineering, vol. 9, no. 2, pp. 476-483, 2017.

[5] H. Ardi, A. Ajami, F. Kardan, and S. N. Avilagh, "Analysis and implementation of a nonisolated bidirectional DC-DC converter with high voltage gain," IEEE Transactions on Industrial Electronics, vol. 63, no. 8, pp. 4878-4888, 2016.

[6] M. Z. Malik, Q. Xu, A. Farooq, and G. Chen, "A new modified quadratic boost converter with high voltage gain," IEICE Electron. Express, 2016.

[7] A. Farooq, Z. Malik, Z. Sun, and G. Chen, "A review of nonisolated high step-down Dc-Dc Converters," International Journal of Smart Home, vol. 9, no. 8, pp. 133-150, 2015.

[8] M. Z. Malik, A. Ali, Q. Xu, and G. Chen, "A new quadratic boost converter with voltage multiplier cell: an analysis and assessment," International Journal of Smart Home, vol. 10, no. 8, pp. 281-294, 2016.

[9] H. Wu, X. Zhan, and Y. Xing, "Interleaved LLC resonant converter with hybrid rectifier and variable-frequency plus phaseshift control for wide output voltage range applications," IEEE Transactions on Power Electronics, vol. 32, no. 6, pp. 42464257, 2016.

[10] D. Thenathayalan, C. Lee, and J.-H. Park, "High-order resonant converter topology with extremely low-coupling contactless transformers," IEEE Transactions on Power Electronics, vol. 31, no. 3, pp. 2347-2361, 2015.
[11] S.-W. Lee and H.-L. Do, "High step-up coupled-inductor cascade boost DC-DC converter with lossless passive snubber," IEEE Transactions on Industrial Electronics, vol. 65, no. 10, pp. 7753-7761, 2018.

[12] A. Farooq, Z. Malik, D. Qu, Z. Sun, and G. Chen, "A threephase interleaved floating output boost converter," Advances in Materials Science and Engineering, vol. 2015, Article ID 409674, 8 pages, 2015.

[13] B. Ahmad, J. Kyyra, and W. Martinez, "Efficiency optimisation of an interleaved high step-up converter," Journal of Engineering, vol. 2019, no. 17, pp. 4167-4172, 2019.

[14] S. B. Mahajan, P. Sanjeevikumar, P. Wheeler, F. Blaabjerg, M. Rivera, and R. Kulkarni, "X-Y converter family: a new breed of buck boost converter for high step-up renewable energy applications," in 2016 IEEE International Conference on Automatica (ICA-ACCA), pp. 1-8, Curico, Chile, 2016.

[15] O. Cornea, G.-D. Andreescu, N. Muntean, and D. Hulea, "Bidirectional power flow control in a DC microgrid through a switched-capacitor cell hybrid DC-DC converter," IEEE Transactions on Industrial Electronics, vol. 64, no. 4, pp. 3012-3022, 2016.

[16] A. Tomaszuk and A. Krupa, "Step-up DC/DC converters for photovoltaic applications-theory and performance," Electrical Review, vol. 89, pp. 51-57, 2013.

[17] M. Z. Malik, H. Chen, M. S. Nazir et al., "A new efficient stepup boost converter with CLD cell for electric vehicle and new energy systems," Energies, vol. 13, no. 7, p. 1791, 2020.

[18] M. D. Siddique, S. Mekhilef, N. M. Shah, and M. A. Memon, "Optimal design of a new cascaded multilevel inverter topology with reduced switch count," IEEE Access, vol. 7, pp. 24498-24510, 2019.

[19] M. D. Siddique, S. Mekhilef, N. M. Shah, J. S. M. Ali, and F. Blaabjerg, "A new switched capacitor $7 \mathrm{~L}$ inverter with triple voltage gain and low voltage stress," IEEE Transactions on Circuits and Systems II: Express Briefs, vol. 67, no. 7, pp. 12941298, 2020.

[20] M. D. Siddique, J. S. M. Ali, S. Mekhilef, A. Mustafa, N. Sandeep, and D. Almakhles, "Reduced switch count based single source 7L boost inverter topology," IEEE Transactions on Circuits and Systems II: Express Briefs, vol. 67, no. 12, pp. 3252-3256, 2020. 